\title{
1 Fifty thousand years of arctic vegetation and megafaunal diet
}

2 Eske Willerslev $1 *$, John Davison $2 *$, Mari Moora $2 *$, Martin Zobel $2 *$, Eric Coissac $3 *$, Mary E.

3 Edwards $4 *$, Eline D. Lorenzen $1,5 *$, Mette Vestergård $1 *$, Galina Gussarova $6,7 *$, James

4 Haile $^{1,8 *}$, Joseph Craine ${ }^{9}$, Gaddy Bergmann ${ }^{10}$, Ludovic Gielly ${ }^{3}$, Sanne Boessenkool $6 \dagger$, Laura

5 S. Epp $6 \dagger$ Peter B. Pearman11, Rachid Cheddadi ${ }^{12}$, David Murray ${ }^{13}$, Kari Anne Bråthen ${ }^{14}$,

6 Nigel Yoccoz ${ }^{14}$, Heather Binney ${ }^{4}$, Corinne Cruaud ${ }^{15}$, Patrick Wincker ${ }^{15}$, Tomasz Goslar 16,17 ,

7 Inger Greve Alsos ${ }^{18}$, Eva Bellemain $6 \dagger$, Anne Krag Brysting ${ }^{19}$, Reidar Elven 6 , Jørn Henrik

8 Sønsteb $\varnothing^{6}$, Julian Murton 20 , Andrei Sher $21 \S$, Morten Rasmussen 1 , Regin Rønn ${ }^{22}$, Tobias

9 Mourier$^{1}$, Alan Cooper ${ }^{23}$, Jeremy Austin ${ }^{23}$, Per Möller ${ }^{24}$, Duane Froese ${ }^{25}$, Grant Zazula ${ }^{26}$,

10 François Pompanon ${ }^{3}$, Delphine Rioux ${ }^{3}$, Vincent Niderkorn ${ }^{27}$, Alexei Tikhonov ${ }^{28}$, Grigoriy

11 Savvinov 29 , Richard G. Roberts 30 , Ross D. E. MacPhee ${ }^{31}$, M. Thomas P. Gilbert ${ }^{1}$, Kurt H.

12 Kjær $^{1}$, Ludovic Orlando ${ }^{1}$, Christian Brochmann $6^{* *} \&$ Pierre Taberlet $^{3 * *}$

14 1. Centre for GeoGenetics, Natural History Museum, University of Copenhagen, Oster Voldgade

15 5-7 DK-1350 Copenhagen K, Denmark.

16 2. Department of Botany, Institute of Ecology and Earth Sciences, University of Tartu, 40 Lai

17 St., 51005 Tartu, Estonia.

18 3. Laboratoire d'Ecologie Alpine (LECA) CNRS UMR 5553, Univ. Joseph Fourier, BP 5338041

19 Grenoble Cedex 9, France.

20 4. Geography and Environment, University of Southampton, Southampton SO17, 1BJ, UK.

21 5. Department of Integrative Biology, University of California Berkeley, 1005 Valley Life

22 Sciences Building, Berkeley, CA 94720, USA.

23 6. National Centre for Biosystematics, Natural History Museum, University of Oslo, P.O. Box 24 1172, Blindern, NO-0318, Oslo, Norway 
25 7. Department of Botany, St. Petersburg State University, Universitetskaya nab. 7/9 199034, St.

26 Petersburg, Russia.

27 8. Ancient DNA Laboratory, Veterinary and Life Sciences School, Murdoch University, 90

28 South Street, Perth, Australia.

29 9. Division of Biology, Kansas State University, Manhattan KS 66506-4901 USA.

30 10. Ecology and Evolutionary Biology, University of Colorado, Boulder, USA.

31 11. Landscape Dynamics Unit, Swiss Federal Research Institute WSL, Zürcherstrasse 111, CH328903 Birmensdorf, Switzerland.

33 12. Institut des Sciences de l'Evolution de Montpellier, UMR 5554 Université Montpellier 2, 34 Bat.22, CC061, Place Eugène Bataillon 34095 Montpellier cedex5, France.

35 13. University of Alaska Museum of the North, Fairbanks AK 99775-6960, USA.

36 14. Department of Arctic and Marine Biology, UiT The Arctic University of Norway, NO-9037 37 Troms $\varnothing$, Norway.

38 15. Genoscope, Institut de Genomique du Commissariat à l'Energie Atomique (CEA), Evry, 39 France.

40 16. Adam Mickiewicz University, Faculty of Physics, Umultowska 85, 61-614 Poznań, Poland.

41 17. Poznań Radiocarbon Laboratory, Poznań Science and Technology Park, Rubież 46, 61-612 42 Poznań, Poland.

43 18. Troms $\varnothing$ University Museum, NO-9037 Troms $\varnothing$, Norway.

44 19. Centre for Ecological and Evolutionary Synthesis, Department of Biosciences, University of 45 Oslo, P.O. Box 1066 Blindern, NO-0316 Oslo, Norway. 
46 20. Permafrost Laboratory, Department of Geography, University of Sussex, Brighton, BN1 9QJ, 47 United Kingdom.

48 21. Institute of Ecology and Evolution, Russian Academy of Sciences, 33 Leninsky Prospect, 49119071 Moscow, Russia.

50 22. Department of Biology, Terrestrial Ecology, Universitetsparken 15, DK- 2100 Copenhagen

$51 \varnothing$, Denmark.

52 23. Australian Centre for Ancient DNA, School of Earth \& Environmental Sciences, University 53 of Adelaide, South Australia, 5005 Australia.

54 24. Department of Geology/Quaternary Sciences, Lund University Sölvegatan 12, SE-223 62 55 Lund, Sweden.

56 25. Department of Earth and Atmospheric Sciences, University of Alberta, Edmonton, Alberta 57 T6G 2E3, Canada.

58 26. Government of Yukon, Department of Tourism and Culture, Yukon Palaeontology Program, 59 PO Box 2703 L2A, Whitehorse, Yukon Territory Y1A 2C6, Canada.

60 27. INRA, UMR1213 Herbivores, F-63122 Saint-Genès-Champanelle, France.

61 28. Zoological Institute of Russian Academy of Sciences, Universitetskaya nab. 1, 199034 Saint62 Petersburg, Russia.

63 29. Institute of Applied Ecology of the North of North-Eastern Federal University, Belinskogo 64 str. 58, 677000 Yakutsk, Republic of Sakha (Yakutia), Russia.

65 30. Centre for Archaeological Science, School of Earth and Environmental Sciences, University 66 of Wollongong, Wollongong, NSW 2522, Australia.

67 31. Division of Vertebrate Zoology/Mammalogy, American Museum of Natural History, New 68 York, NY 10024, USA. 
$69 *$ These authors contributed equally and should be regarded joint first authors

$70 * *$ These authors should be regarded joint senior authors

71 §Deceased 2008

$72 †$ Present addresses: Centre for Ecological and Evolutionary Synthesis, Department of

73 Biosciences, University of Oslo, P.O Box 1066, Blindern, NO-0318, Oslo, Norway;.Alfred

74 Wegener Institute, Helmholtz Centre for Polar and Marine Research, Research Unit Potsdam,

75 Telegrafenberg A 43, 14473 Potsdam, Germany; SpyGen, Savoie Technolac, 17 allée du lac

76 Saint André, BP 274, 73375 Le Bourget-du-Lac Cedex, France. 
77 Although it is generally agreed that the arctic flora is among the youngest and least diverse

78 on Earth, the processes that shaped it are poorly understood. Here we present 50 thousand

79 years (kyr) of arctic vegetation history, derived from the first large-scale ancient DNA

80 metabarcoding study of circumpolar plant diversity. For this interval we additionally

81 explore nematode diversity as a proxy for modelling vegetation cover and soil quality, and

82 diets of herbivorous megafaunal mammals, many of which became extinct around $10 \mathrm{kyr}$

83 BP (before present). For much of the period investigated, arctic vegetation consisted of dry

84 steppe tundra dominated by forbs (non-graminoid herbaceous vascular plants). During the

85 Last Glacial Maximum (25-15 kyr BP), diversity declined markedly, although forbs

86 remained dominant. Much changed after $10 \mathrm{kyr} \mathrm{BP}$, with the appearance of moist tundra

87 dominated by woody plants and graminoids. Our analyses indicate that both graminoids

88 and forbs would have featured in megafaunal diets. As such our findings question the

89 predominance of a late Quaternary graminoid-dominated arctic "mammoth steppe". 
90 It can be argued that arctic vegetation during the proximal Quaternary (the last $c .50 \mathrm{kyr}$ ) is less

91 well understood than the ecology and population dynamics of the mammals that consumed it,

92 despite the overall uniformity and low floristic diversity of Arctic vegetation ${ }^{1-2}$ Analyses of

93 vegetation changes during this interval have been based mainly on fossil pollen. Although highly

94 informative, records tend to be biased toward high pollen producers such as many graminoids

95 (grasses, sedges, and rushes) and Artemisia, which can obscure the abundance of other forms

96 such as many insect-pollinated forbs ${ }^{1}$. Arctic pollen records are rarely comprehensively

97 identified to species level, which underestimates actual diversity ${ }^{3}$. These problems are to some

98 extent ameliorated by plant macrofossil studies (e.g. ${ }^{4}$ ), which may provide detailed records of

99 local vegetation. However, macrofossil studies are far less common, have their own taxonomic

100 constraints, and usually cannot provide quantitative estimates of abundance.

101 In recent years, a complementary approach has emerged that utilizes plant and animal ancient

102 DNA preserved in permafrost sediments ${ }^{5}$. Such environmental DNA ${ }^{11}$ does not derive primarily

103 from pollen, bones, or teeth, but from above- and below-ground plant biomass, faeces, discarded

104 cells and urine preserved in sediments ${ }^{6-8}$. Like macrofossils, environmental DNA appears to be

105 local in origin ${ }^{9-12}$ and in principle the survival of a few fragmented DNA molecules is sufficient

106 for retrieval and taxonomic identification ${ }^{13}$.

107 Environmental DNA can supply the fraction of the plant community not readily identifiable by

108 pollen analysis and, to some extent, macrofossils, particularly in vegetation dominated by non-

109 woody growth forms ${ }^{6}$. For most plant groups, DNA permits identification at lower taxonomic

110 levels than pollen ${ }^{14}$. Additionally, environmental DNA records have proven to reflect not only

111 the qualitative but also the quantitative diversity of aboveground plant ${ }^{12}$ and animal taxa ${ }^{8}$, as

112 determined from modern sub-surface soils.

113 Leaching of DNA through successive stratigraphic zones may be an issue in temperate

114 conditions ${ }^{8,10}$ but not in permafrost ${ }^{5}$ or in sediments that have only recently thawed ${ }^{15}$. Re-

115 deposition of sediments and organics can confound results, which is also the case for pollen and

116 macrofossils ${ }^{6,16}$, but can be avoided and accounted for by careful site selection and by excluding

117 rare DNA sequence reads ${ }^{16}$. For Quaternary permafrost settings, at least, taphonomic bias due to

118 differences in DNA survival across plant groups does not appear to be of concern (see Methods 
119 section 4.0 on taphonomy), as has been shown by a comparative permafrost ancient DNA study

120 of plants and their associated fungi ${ }^{17}$.

\section{Reconstruction of Arctic vegetation from permafrost samples}

122 We collected 242 sediment samples from 21 sites across the Arctic (Fig. 1, Extended Data Table

123 1). Ages were determined by accelerator mass spectrometry radiocarbon $\left({ }^{14} \mathrm{C}\right)$ dating, and are

124 reported here in thousands of calibrated (calendar) years BP (Extended Data Figure 1,

125 Supplementary Data 1). We sequenced the short P6 loop sequence of the trnL plastid region and

126 a part of the ITS1 spacer region through metabarcoding (Methods section 3.0), generating a total

127 of 14,601,839 trnL plant DNA sequence reads and 1,652,857 ITS reads. Reads were identified

128 by comparison with (i) the arctic $t r n \mathrm{~L}$ taxonomic reference library ${ }^{14}$, which we extended with

129 ITS sequences for three families; (ii) a new north boreal $\operatorname{trn} \mathrm{L}$ taxonomic reference library

130 constructed by sequencing 1,332 modern plant samples representing 835 species; and (iii)

131 GenBank, using the program ecoTag (Supplementary Data 2, Methods section 3.0). Basic

132 statistics, in silico analyses, and additional experiments were carried out to check data reliability

133 (Extended Data Figure 2, Extended Data Table 2). We grouped the identified molecular

134 operational taxonomic units (MOTUs) into three distinct intervals (Fig. 2a): i) pre-LGM (50-25

135 kyr BP), a period of fluctuating climate; (ii) LGM (25-15 kyr BP), a period of constantly cold

136 and dry conditions; and (iii) post-LGM (15-0 kyr BP), the current interglacial, characterised by

137 relatively higher temperatures ${ }^{17}$.

\section{Shifts in plant composition and lower diversity during the LGM}

139 To address compositional changes in vegetation across space and time we used a generalised

140 linear model and permutational multivariate analysis of variance (Permanova) (Supplementary

141 Data 3, Methods section 5.0). We find that (i) the composition of plant MOTU assemblages

142 differed significantly across the three intervals (pseudo- $\mathrm{F}=6.77, p<0.001$, Extended Data

143 Figure 3a-e), with pre-LGM and post-LGM plant assemblages differing the most (Extended Data

144 Figure 3f); (ii) the greater the spatial distance separating a pair of samples within each time

145 period, the less similar their composition ( $p<0.001)$; and (iii) LGM assemblages were most

146 homogeneous across space and post-LGM assemblages were most heterogeneous (Fig. 2). 
147 LGM pollen spectra show high floristic richness compared to other intervals (e.g. $\left.{ }^{1}\right)$. This is due

148 to the limited occurrence of woody taxa with high pollen production, which in turn

149 proportionately emphasizes lower pollen-producing taxa. In contrast, our DNA data reveal that

150 plant diversity was lowest during LGM relative to other intervals (Fig. 2a). Plant assemblages

151 became more similar to each other and the estimated number of MOTUs decreased from pre-

152 LGM to LGM (Fig. 2a), with many taxa absent that had previously been well represented (Fig.

153 2b). In addition, while the LGM flora was largely a subset of the pre-LGM flora, the post-LGM

154 flora was different (Fig. 2b), with pronounced geographic differentiation (Fig. 2c).

\section{Steppe-tundra}

156 Due to the low taxonomic resolution of previously published vegetation reconstructions, it

157 remains undetermined whether arctic vegetation during the last part of the Quaternary was a

158 form of tundra or more like steppe (e.g. ${ }^{18,19}$ ). Small-scale contemporary analogues range from

159 low-productivity fellfields and cryoxeric steppe communities to more productive dry arctic

160 steppe-to-tundra gradients. Our sediment DNA plant sequence data from 50-12 kyr BP

161 encompass taxa that typify both tundra and arctic steppe environments. These include taxa that

162 are today typical of dry and/or disturbed sites (e.g. Bromus pumpillianus, Artemisia frigida,

163 Plantago canescens, Anemone patens), saline soils (Puccinellia, Armeria), moist habitats

164 (Caltha) and rocky or fellfield habitats (Dryas, Draba), plus a woody component dominated by

165 Salix (Supplementary Data 4 and 5). A spatial and/or temporal mosaic of plant communities is

166 indicated (Methods section 6.0), as is seen in floristically rich macrofossil records ${ }^{4}$. The most

167 common MOTU in the pre-LGM and LGM samples is Anthemidae Group 1 (Artemisia,

168 Achillea, Chrysanthemum, Tanacetum), which underscores the importance in regional pollen

169 assemblages of Asteraceae in general and Artemisia in particular ${ }^{1}$. Equisetum and Eriophorum

170 are important only in postglacial assemblages, reflecting moister soil conditions. Increases in

171 aquatic taxa (Supplementary Data 4 and 5) also indicate a predominance of moister substrates in

172 the later part of the post-LGM period. These findings indicate a shift from dry steppe-tundra to

173 moist tundra in the early part of the post-LGM period-a change widely reported in other proxy

174 studies. 
175 Nematode assemblage composition is known to change significantly with vegetation cover ${ }^{20}$ 176 moisture ${ }^{21}$ and organic resource inputs ${ }^{22}$. Therefore, to obtain a complementary proxy for

177 vegetation cover and soil quality, we characterized the soil nematode fauna of contemporary

178 mesic shrub tundra and subarctic steppe on well-drained loess soils in Yukon Territory, Canada

179 (Fig. 1, Extended Data Table 3). The relative proportion of the nematode families

180 Teratocephalidae and Cephalobidae varied among vegetation types $(p<0.001$, nested ANOVA), 181 and indicator species analysis ${ }^{23}$ confirmed that Teratocephalidae (indicator value $=0.98, p=$ 1820.001 ) and Cephalobidae (indicator value $=0.98, p=0.001$ ) are very good indicators of tundra 183 and steppe vegetation, respectively (Fig. 3). These findings are in agreement with previous 184 studies restricted to subarctic Sweden ${ }^{24,25}$ and alpine and subalpine habitats ${ }^{26-27}$. We amplified 185 short DNA sequences from these two taxa from 17 sediment samples analysed for plant DNA 186 from Yukon and northeastern Siberia. We detected Cephalobidae DNA in almost all samples, 187 while Teratocephalidae was detected at a higher frequency in samples younger than $10 \mathrm{kyr}$ BP 188 than in the pre-LGM and LGM samples (Extended Data Table 4). These results support our 189 inferences from plant sequence data and indicate a transition from relatively dry tundra and 190 steppe towards more moist tundra during the post-LGM interval.

\section{Forb dominance and megafaunal diets}

192 To assess structural and functional shifts in the plant assemblages, we investigated temporal 193 changes in the relative abundance of different growth forms. Our DNA results show that pre-

194 LGM vegetation was dominated by forbs, the relative share of which increased during the LGM, 195 whereas graminoids constituted less than $20 \%$ of the total read count (Fig. 4a). These results 196 persisted when we corrected for observed modern representational bias ${ }^{12}$ (Methods sections 4.0 197 and 5.3).

198 Continued forb dominance during the LGM implies that similar proportions of forbs and 199 graminoids were maintained through this period, despite the significant decline in floristic 200 diversity (Fig. 2a,b). Our findings contrast with pollen-based reconstructions, which have 201 emphasized dominance of graminoids in the unglaciated Arctic and adjacent regions, particularly 202 during the LGM, and exemplified by the widely-used term "mammoth-steppe" ${ }^{19}$. Rather, our 203 results show that vegetation was forb-dominated in both overall abundance of MOTUs and in 
204 floristic richness (Fig. 4a,b, Extended Data Figure 3g,h), in agreement with macrofossil data that

205 show a diversity of forbs of mixed ecological preference (e.g. ${ }^{4}$ ).

206 We explored whether forbs were prominent in habitats favoured by megafauna by analysing 25

207 dated (47-20 kyr BP) sediment samples from Main River, Siberia, using trnL plastid plant and

208 16S mtDNA mammal primers. We found that the mean proportion of forbs was higher in

209 samples from which herbivorous megafaunal DNA had been retrieved $(n=18$; e.g. woolly

210 mammoth, woolly rhinoceros, horse, reindeer and elk) than in samples lacking such DNA ( $\mathrm{n}=7$;

211 Fig. 4c, Extended Data Table 5). Although suggestive of co-occurrence of megafauna in forb-

212 dominated settings, these results should be regarded as tentative, and further studies are needed

213 to verify if this is indeed a general trend.

214 We also investigated whether megafaunal diets revealed the level of forb dominance observed in

215 permafrost sediment samples. Using standardised methods, we genetically characterised

216 intestinal/stomach contents and coprolites recovered from 8 specimens of woolly mammoth,

217 woolly rhinoceros, bison and horse from Siberia and Alaska, dated > 55-21 kyr BP (Extended

218 Data Table 6, Methods sections 3.0 and 7.0). Although ingested plant remains are often difficult

219 to identify morphologically, they can be accurately identified ${ }^{28,29}$ and roughly quantified ${ }^{30}$ using

220 DNA. The majority of these samples are dominated by forbs, which comprise $0.63 \pm 0.12$ of the

221 sequences, compared to $0.27 \pm 0.16$ expressing graminoid sequences (Fig. 4d, Supplementary

222 Data 6). These results suggest that megafaunal species supplemented their diets with high-

223 protein forbs rather than specializing more or less exclusively on grasses.

224 To confirm the reliability of our $t r n \mathrm{~L}$ approach for estimating herbivore diet, we analysed 50

225 rumen samples of sheep-feed diets with varying proportions of forbs (white clover, Trifolium

226 repens) and graminoids (ryegrass, Lolium perenne) (Methods section 5.4). As seen in Figure 4e,

227 the Pearson correlation coefficient between the actual fraction of forbs in these diets and the

228 proportion of forbs estimated with the DNA-based approach was highly significant $\left(\mathrm{r}^{2}=0.75, p<\right.$

$\left.22910^{-15}\right)$.

230 Perspectives 
231 Our observations of high forb abundance in the terminal Pleistocene may merely reflect

232 vegetation response to glacial climates, but there are other possibilities ${ }^{1}$. An abundant

233 megafauna would have caused significant trampling ${ }^{31}$, enhancing gap-based recruitment ${ }^{32}$,

234 which could favour forbs ${ }^{33}$. Coupled with nitrogen input from wide-ranging herbivores ${ }^{34}$, forbs

235 may out-compete grasses ${ }^{35}$. Furthermore, a diet rich in forbs may help explain how numerous

236 large animals were sustained; forbs may be more nutrient-rich (e.g. ${ }^{35}$ ) and more easily digested

$237{ }^{36}$ than grasses. However, a feedback loop that maintained nutritious and productive forage and

238 supported large mammalian populations in glacial climate regimes may have been impossible to

239 maintain after deglaciation, as $\mathrm{C}: \mathrm{N}$ ratios increased with global warming ${ }^{37}$, and the potential

240 breakdown of the megafauna-forb interaction would have been exacerbated by declining

241 mammalian populations. In contemporary tundra and steppe (the latter often called grasslands),

242 graminoids are generally perceived to be the dominant growth form in large herbivore habitats

243 (e.g. ${ }^{38,39}$ ). Our data, which unearth $50 \mathrm{kyr}$ of arctic vegetation history, call this perception into

244 question.

\section{Methods summary}

246 Plant fragments or soil matrix organics were ${ }^{14} \mathrm{C}$-dated using accelerator mass spectrometry and

247 measured ${ }^{1}$ ages were converted into calendar years ${ }^{40}$. Permafrost sampling ${ }^{5}$, DNA extraction

$248{ }^{11}$, PCR amplification ${ }^{41}$ and taxon identification (e.g. ${ }^{12}$ ) followed established procedures. Most

249 vascular taxa are covered by ${ }^{42}$, and nomenclature is provided accordingly; for the remaining

250 taxa nomenclature follows ${ }^{43}$. Dissimilarity between plant assemblages was quantified using

251 pairwise Bray-Curtis distance ${ }^{44}$. Variation in assemblage dissimilarity was decomposed using

252 Permutational Multivariate Analysis of Variance (Permanova ${ }^{45}$ ) and visualised using non-metric

253 multidimensional scaling ${ }^{46,47}$. We used a distance decay approach ${ }^{49}$ and a generalized linear

254 model to model variation in plant community assemblages over space and time. Growth form

255 composition of communities was compiled from species trait databases ${ }^{49}$. Differences in the trait

256 composition of assemblages in adjacent climatic periods were compared to a null model

257 assuming random assortment from the previous interval. Nematode faunas of 35 contemporary

258 sediment samples were morphologically determined. Presence of two indicator families

259 (Teratocephalidae for tundra and Cephalobidae for steppe) was genetically determined in 17 
ancient sediment samples. Megafaunal DNA and faeces and gut content were determined genetically following established methods. For a detailed discussion, see Methods.

\section{References}

263 1. Anderson, P. M., Edwards, M. E. \& Brubaker, L. B. in The Quaternary Period in the $264 \quad$ United States. Developments in Quaternary Science (Gillespie, A. E., Porter, S. C. \& 265 Atwater, B. F.) 427-440 (Elsevier, New York, 2003).

266 2. Murray, D. F. in Arctic and alpine biodiversity: Patterns, causes and ecosystem 267 consequences (Chapin, F. S. \& Körner, C.) 21-32 (Springer, Heidelberg, 1995).

268 3. Lamb, H. F. \& Edwards, M. E. in Vegetation History. Handbook of Vegetation Science 7 269

4. Kienast, F., Schirrmeister, L., Siegert, C. \& Tarasov, P. E. Palaeobotanical evidence for warm summers in the East Siberian Arctic during the last cold stage. Quaternary

273 5. Willerslev, E. et al. Diverse plant and animal genetic records from Holocene and

6. Jorgensen, T. et al. A comparative study of ancient sedimentary DNA, pollen and macrofossils from permafrost sediments of northern Siberia reveals long-term vegetational stability. Mol. Ecol. 21, 1989-2003 (2012).

$2787 . \quad$ Lydolph, M. C. et al. Beringian paleoecology inferred from permafrost-preserved fungal DNA. Appl Environ Microbiol 71, 1012-1017 (2005).

280 8. Andersen, K. et al. Meta-barcoding of 'dirt' DNA from soil reflects vertebrate biodiversity. Mol. Ecol. 21, 1966-1979 (2012).

9. Parducci, L. et al. Glacial Survival of Boreal Trees in Northern Scandinavia. Science 335, 1083-1086 (2012).

284 10. Haile, J. et al. Ancient DNA chronology within sediment deposits: Are paleobiological 285 reconstructions possible and is DNA leaching a factor? Molecular Biology and Evolution 24, 982-989 (2007).

11. Haile, J. et al. Ancient DNA reveals late survival of mammoth and horse in interior Alaska. Proc. Natl. Acad. Sci. U.S.A. 106, 22352-22357 (2009).

12. Yoccoz, N. G. et al. DNA from soil mirrors plant taxonomic and growth form diversity. 
Mol. Ecol. 21, 3647-3655 (2012).

291 13. Willerslev, E. \& Cooper, A. Ancient DNA. Proc. Biol. Sci. 272, 3-16 (2005).

292 14. Sønstebø, J. H. et al. Using next-generation sequencing for molecular reconstruction of past Arctic vegetation and climate. Molecular Ecology Resources 10, 1009-1018 (2010).

294 15. Hebsgaard, M. B. et al. The farm beneath the sand-An archaeological case study on

16. Arnold, L. J. et al. Paper II - Dirt, dates and DNA: OSL and radiocarbon chronologies of perennially frozen sediments in Siberia, and their implications for sedimentary ancient DNA studies. Boreas 40, 417-445 (2011).

17. Hopkins, D. M. in Paleoecology of Beringia (Hopkins, D. M., Matthews, J. V., Jr,

18. Ritchie, J. C. \& Cwynar, L. C. in Paleoecology of Beringia (Hopkins, D. M., Matthews,

19. Guthrie, R. D. Frozen Fauna of the Mammoth Steppe. (University of Chicago Press,

306 20. Yeates, G. W. Diversity of nematode faunae under three vegetation types on a pallic soil in Otago, New Zealand. New Zealand Journal of Zoology 23, 401-407 (1996).

22. Yeates, G. W. Nematodes as soil indicators: functional and biodiversity aspects. Biology and Fertility of Soils 37, 199-210 (2003).

312 23. Dufrêne, M. \& Legendre, P. Species assemblages and indicator species: the need for a

313 flexible asymmetrical approach. Ecological Monographs 67, 345-366 (1997).

314 24. Ruess, L., Michelsen, A. \& Jonasson, S. Simulated climate change in subarctic soils:

315 responses in nematode species composition and dominance structure. Nematology $\mathbf{1}$, $316 \quad 513-526(1999)$.

317 25. Sorensen, L. I., Mikola, J., Kytoviita, M.-M. \& Olofsson, J. Trampling and spatial 318 heterogeneity explain decomposer abundances in a sub-Arctic grassland subjected to 319 simulated reindeer grazing. Ecosystems 12, 830-842 (2009).

320 26. Popovici, I. \& Ciobanu, M. Diversity and distribution of nematode communities in 
grasslands from Romania in relation to vegetation and soil characteristics. Appl Soil Ecol 14, 27-36 (2000).

323 27. Hoschitz, M. \& Kaufmann, R. Nematode community composition in five alpine habitats. $324 \quad$ Nematology 6, 737-747 (2004).

325 28. Poinar, H. N. et al. Molecular coproscopy: Dung and diet of the extinct ground sloth Nothrotheriops shastensis. Science 281, 402-406 (1998).

327 29. Hofreiter, M. et al. A molecular analysis of ground sloth diet through the last glaciation. 328 Mol. Ecol. 9, 1975-1984 (2000).

329 30. Soininen, E. M. E. et al. Analysing diet of small herbivores: the efficiency of DNA 330 barcoding coupled with high-throughput pyrosequencing for deciphering the composition of complex plant mixtures. Front Zool 6, 16-16 (2009).

332 31. Zimov, S. A., Zimov, N. S., Tikhonov, A. N. \& Chapin, F. S. I. Mammoth steppe: a 333 high-productivity phenomenon. Quaternary Science Reviews 57, 26-45 (2012).

334 32. Owen-Smith, N. Pleistocene Extinctions: The Pivotal Role of Megaherbivores. 335 Paleobiology 13, 351-362 (1987).

336 33. Austrheim, G. \& Eriksson, O. Recruitment and life-history traits of sparse plant species in subalpine grasslands. Canadian Journal of Botany-Revue Canadienne De Botanique

339 34. Wardle, D. A. \& Bardgett, R. D. Human-induced changes in large herbivorous mammal density: the consequences for decomposers. Frontiers in Ecology and the Environment

342 35. Gusewell, S. N : P ratios in terrestrial plants: variation and functional significance. New Phytologist 164, 243-266 (2004).

344 36. Cornelissen, J. et al. Leaf digestibility and litter decomposability are related in a wide range of subarctic plant species and types. Functional Ecology 18, 779-786 (2004).

346 37. McLauchlan, K. K., Williams, J. J., Craine, J. M. \& Jeffers, E. S. Changes in global 347 nitrogen cycling during the Holocene epoch. Nature 495, 352-355 (2013).

348 38. van der Wal, R. Do herbivores cause habitat degradation or vegetation state transition? 349 Evidence from the tundra. Oikos 114, 177-186 (2006).

350 39. Brathen, K. A. et al. Induced shift in ecosystem productivity ? Extensive scale effects of 351 abundant large herbivores. Ecosystems 10, 773-789 (2007). 
352 40. Reimer, P. J. et al. Intcal09 and Marine09 radiocarbon age calibration curves, 0-50,000 353 years cal BP. Radiocarbon 51, 1111-1150 (2009).

354 41. Taberlet, P. et al. Power and limitations of the chloroplast trnL (UAA) intron for plant $355 \quad$ DNA barcoding. Nucleic Acids Research 35, e14 (2007).

356 42. Elven, R., Murray, D. F., Razzhivin, V. Y. \& Yurtsev, B. A. Annotated Checklist of the 357 Panarctic Flora (PAF). (Natural History Museum, University of Oslo, 2011). at <http://nhm2.uio.no/paf/>

43. Sayers, E. W. et al. Database resources of the National Center for Biotechnology

44. Bray, J. R. \& Curtis, J. T. An Ordination of the Upland Forest Communities of Southern

45. Anderson, M. J. A new method for non-parametric multivariate analysis of variance. Austral Ecology 26, 32-46 (2001).

46. Shepard, R. N. The analysis of proximities: multidimensional scaling with an unknown distance function. I. Psychometrika (1962).

367 47. Shepard, R. N. The analysis of proximities: multidimensional scaling with an unknown

48. Nekola, J. C. \& White, P. S. The distance decay of similarity in biogeography and ecology. Journal of Biogeography 26, 867-878 (1999).

49. Klotz, S., Kühn, I. \& Durka, W. BIOLFLOR. (Bundesamt für Naturschutz, Bonn, 2002).

372 50. group, N. D. IGBP PAGES/World Data Center for Paleoclimatology Data Contribution Series 2008-034 NOAA/NCDC Paleoclimatology Program, Boulder CO, USA. The Holocene (2008).

377 www.nature.com/nature.

\section{Acknowledgements}

379 We thank A. Lister, R. D. Guthrie, M. Hofreiter, L. Parducci, for very valuable thoughts and 380 fruitful discussions of our findings and $\mathrm{K}$. Andersen for help identifying possible contamination. 381 We thank T. B. Brand, P. S. Olsen, V. Mirré, L. J. Gillespie, J. M. Saarela, J. Doubt, M. 
382 Lomonosova, D. Shaulo, J. E. Eriksen, Steffi Ickert-Bond ,T. Ager, D. Bielman ,M. Hajibabaei,

383 A. Telka and S. Zimov for help and providing samples. We thank the Danish National

384 Sequencing Centre. This work was supported by the European Union 6th framework project

385 ECOCHANGE (GOCE-2006-036866, coordinated by P. Taberlet), the Danish National Research

386 Foundation (Centre of Excellence to E. Willerslev), the European Regional Development Fund

387 (Centre of Excellence FIBIR and SF0180098s08 to J. Davison, M. Moora, M. Zobel), the

388 Research Council of Norway (191627/V40 to C. Brochmann), the Australian Research Council

389 (DP0558446 to R.G. Roberts), a Marie Curie International Outgoing Fellowship (PIOF-GA-

390 2009-253376 to E.D. Lorenzen) and a Carlsberg Foundation (to M. Vestergård).

391 Author contributions

392 The paper represents the joint efforts of several research groups, headed by various people within 393 each group. Rather than publishing a number of independent papers, we have chosen to combine

394 our data in this paper in the belief that this creates a more comprehensive story. The authorship 395 reflects this joint effort. The ECOCHANGE Team designed and initiated the project. EW, MEE, 396 JM, EDL, MV, GG, JH, JC, IGA, PM, DF, GZ, AT, JA, AS, GS, RGR, RDEM, MTPG, and KK 397 collected the samples. GG, RE, AKB, JHS, CB, LG, EC and PT constructed the plant DNA 398 taxonomic reference libraries and provided taxonomic assignments of the sediment data with 399 input from IGA, EB, SB, LSE, MEE, and DM. EDL, MV, JH, LSE, SB, CC, PW, LG, GG and

400 JHS conducted the genetics lab work. TG did the dating. FP, DR, and VN produced and analysed 401 the data concerning the reliability of the $\operatorname{trn} \mathrm{L}$ approach for estimating herbivore diet. JD, MM, 402 MZ, EC, MV, MR, JC, SB, PBP, HB, RR, TM and PT did the analyses. EDL produced the 403 figures. EW wrote most of the text with input from all authors, in particular JD, MM, MZ, EDL, 404 MEE, MV, PBP, DM, KAB, NY, LO, CB, PT, and RDEM.

\section{Author information}

406 All the raw and filtered data concerning plants, nematodes, megafauna and sheep diet are 407 available from the Dryad Digital Repository: http://doi.org/XXXXXX/XXXXXX. The authors 408 declare no competing financial interests. Correspondence and requests for materials should be 409 addressed to E.W. (ewillerslev@ snm.ku.dk). 
411 Figure 1. Sample localities. A total of 242 permafrost samples were collected from 21 sites, 412 shown by green dots. Eight ancient megafauna gut and coprolite samples $(\mathrm{A}-\mathrm{H})$ are shown by

413 grey hollow circles, seven modern nematode localities by grey hollow triangles.

414 Figure 2. Taxonomic diversity of arctic plant assemblages during the last 50 kyr. Taxon 415 composition was estimated by high-throughput sequencing of DNA from 242 permafrost 416 samples. A total of 154 molecular operational taxonomic units (MOTUs) were detected. a, Index 417 of ambient temperature (continuous line; oxygen isotope concentration, GRIP ${ }^{50}$ ) and estimated 418 MOTU number (horizontal bars; second-order jackknife), are shown for three palaeoclimatic 419 periods: pre-LGM (> $25 \mathrm{kyr}, \mathrm{n}=149$ ), LGM (last glacial maximum; 25-15 kyr, $\mathrm{n}=32$ ) and 420 post-LGM (<15 kyr, $\mathrm{n}=61)$. b, MOTU counts recorded uniquely in each palaeoclimatic period 421 and shared among periods. c, Modelled decline in similarity (1-Bray-Curtis dissimilarity) 422 between pairs of plant assemblages from the same palaeoclimatic period in relation to the spatial 423 distance separating them.

424 Figure 3. Proportional abundance of two families (Teratocephalidae - dark; Cephalobidae 425 light) among the total soil nematode community at contemporary tundra and steppe sites in 426 Yukon, Canada. Letters a-g correspond to sample localities (Fig. 1). Median (central dot), 427 quartile (box), maximum and minimum (whiskers) and outlying values (points) are shown.

428 Figure 4. Plant growth form composition over time and across sample types, estimated by high429 throughput sequencing of DNA from 242 permafrost samples. a, Proportions of DNA reads 430 corresponding to taxa exhibiting different growth forms, binned over $5 \mathrm{kyr}$ time intervals. The 431 analysis included all sediment samples except 21 Svalbard samples and three further samples 432 where no growth form information was available. b, Number of MOTUs exhibiting different 433 growth forms as a proportion of total MOTU richness in all informative samples for each 434 palaeoclimatic period. c, The proportional abundance of forbs in samples from Main River, 435 Siberia (dated 47,100-19,850 yr BP) where megafauna were or were not detected. d, Proportions 436 of DNA reads corresponding to different growth forms in megafauna diet, determined from 437 analysis of eight gut and coprolite samples from late Quaternary megafauna species (woolly 
mammoth, woolly rhinoceros, bison and horse). Letters A-H correspond to the individual samples (Fig. 1). The $95.4 \%$ calibrated age range of each sample is shown; ' $>55$ ' indicates that

440 the sample was too old to provide a finite radiocarbon age. e, Reliability of the trnL approach for 441 estimating forb and graminoid abundance in diet analyses. Sheep were fed with known amounts 442 of forbs (Trifolium repens) and graminoids (Lolium perenne), and the rumen content analyzed 443 using the same DNA-based approach as implemented above. Orange dots and lines represent the 444 means and standard errors for diets containing different fractions of forbs. The grey line is a 445 linear model fit. Numbers immediately below the columns in $\mathbf{a}, \mathbf{b}$, and $\mathbf{c}$ indicate sample sizes. 446 Median (central bar), quartile (box), maximum and minimum (whiskers) values are shown in a 447 and c.

448 Extended Data Figure 1. Permafrost sample locality details. a, Radiocarbon dating chronology 449 for the main section at the Main River site, Russia, from which nearly all Main River samples are 450 derived; b, View of the 2009 Duvanny Yar exposure, NE Siberia; c, yedoma sandy silt in upper 451 c. $12 \mathrm{~m}$ of the exposure at Duvanny Yar exposure, NE Siberia. A large syngenetic ice wedge (top 452 centre) within the yedoma is truncated by a thaw unconformity at a depth of $c .1 .9 \mathrm{~m}$ below the 453 ground surface, marking the maximum post-glacial thaw depth after deposition of the yedoma 454 had ended. Persons for scale, with DNA sediment sample holes to the right of the person on 455 right; d, Calibrated radiocarbon date distributions plotted against depth above river level at 456 Duvanny Yar exposure, NE Siberia. Although there are some finite dates below $20 \mathrm{~m}$, the 457 general curve shape suggests the radiocarbon dating limit occurs at about this level. The two 458 Svalbard sites at $\mathbf{e}$, Colesdalen and $\mathbf{f}$, Endalen.

459 Extended Data Figure 2. MOTU characterization and data consistency. (a-c) Graphs showing 460 the consistency of the DNA-based approach using permafrost samples across the different time 461 periods: a, average marker size per sample; $\mathbf{b}$, number of reads per sample; c, number of taxa per 462 sample. d, WebLogos showing the match between the $g h$ primers and their target sequences in 463 the main plant families involved in the estimation of the proportions of forbs and graminoids ${ }^{70}$.

464 Extended Data Figure 3. Temporal classification of samples, assemblage variation in time and 465 data robustness. a-d (top panel), K-means clustering of permafrost plant assemblages: a cluster 466 identity of samples derived from pre-LGM, LGM and post-LGM periods for values of $\mathrm{k}$ between 
4672 and 10. Each bar represents a separate sample; different colours reflect different cluster

468 identities b, The Calinski-Harabasz criterion for different levels of $\mathrm{k}$. Higher values indicate

469 stronger support for a level of partitioning. c,d Heat maps showing the proportional occurrence

470 of samples from pre-LGM, LGM and post-LGM periods in different clusters, for $\mathrm{k}=2$ (c) and

$471 \mathrm{k}=3(\mathbf{d})$. Colours vary from red (low values) to white (high values). $\mathbf{e}-\mathbf{g}$ (middle panel)

472 Assemblage variation in time and space: e, Nonmetric multidimensional scaling (NMDS)

473 ordination revealed significant variation (Permanova $p<0.01$ ) in fossil/ancient plant assemblage

474 composition during the three palaeoclimatic periods; $\mathbf{f}$, The effect of spatial distance on

475 similarity when assemblages from different palaeoclimatic periods were compared. The vertical

476 axis represents similarity in floristic composition measured as 1-Bray-Curtis similarity, the

477 horizontal axis depicts ln of distance between sampled communities in kilometres. The greater

478 the spatial distance between pairs of assemblages, the more dissimilar they were. However, the

479 rate of the decay differed depending on which two climatic periods were compared (full model $p$

$480<0.001)$. The weakest distance decay in similarity was observed in the case of comparisons

481 between pre-LGM and post-LGM assemblages. Even if pre-LGM and post-LGM samples came

482 from the same geographic area, their floristic compositions were dissimilar; $\mathbf{g}$, Results of

483 randomisation tests. Mean proportional composition of different growth form types in LGM and

484 post-LGM samples. The bars around sample means indicate 95\% quantiles derived from 999

485 bootstrap replicates (where bootstrap $\mathrm{N}$ was set to the number of samples in the post-LGM data

486 set; see methods for details). h (lower panel) Counts of MOTUs exhibiting different growth

487 forms binned over 5 kyr time intervals. The analysis included 218 of the 242 sediment samples,

488 as described in Figure 4. Numbers immediately below the columns indicate sample sizes.

489 Median (central bar), quartile (box), maximum and minimum (whiskers) counts are shown.

490 Extended Data Table 1. Site information of the 21 permafrost localities (shown in main text 491 Fig. 1).

492 Extended Data Table 2. Statistics regarding length of the P6 loop amplified with the gh primers

$493{ }^{42}$ for the most important plant families of the two growth forms (graminoids and forbs). These

494 data were estimated from the arctic/boreal database built for this study. 
495 Extended Data Table 3. Locality information of the seven contemporary tundra and steppe sites 496 in Yukon, Canada, which were analysed for nematode faunal composition (shown in main text 497 Fig. 3). Letters in parentheses refer to locality codes used in main text Figs. 1 and 3.

498 Extended Data Table 4. Proportion of 17 permafrost sediments with sequences of the two 499 indicator nematode families Cephalobidae and Teratocephalidae.

500 Extended Data Table 5. Herbivorous mammal taxa derived from Main River permafrost 501 samples for which plant data were available.

502 Extended Data Table 6. Sample information of the eight megafauna gut and coporolite samples 503 (shown in main text Fig. 1).

504 
506 Site details and related publications are provided in Extended Data Table 1. The sampled sites

507 are generally well characterised stratigraphically, but not all details are published. Complete site

508 and sample information is available from the ECOCHANGE database manager

509 (H.A.Binney@ soton.ac.uk) and the Dryad database (also see section 8.0 for further details on

510 sites). The samples are of mixed provenance: the majority of samples representing the pre-LGM

511 ( $\mathrm{n}=149)$ and LGM ( $\mathrm{n}=32)$ come from exposures of frozen 'ice-complex' deposits, in which the

512 clastic component (silt and fine sand) derives mainly from aeolian deposition and surface runoff

513 in terrestrial permafrost settings characterized by ice-wedge polygons (e.g. ${ }^{23}$ ), whereas most of

514 the post-LGM samples $(\mathrm{n}=61)$ come from modern soil and peat $(37 \%)$, aeolian sediment $(30 \%)$,

515 thermokarst-lake infill (13\%) and fluvial terrace (11\%) sequences, and a few samples of mixed

516 origin (9\%). In most cases, frozen sediment samples were extracted by horizontal drilling using

517 established protocols to guard against sample-based contamination 5,6,53,54 and were kept frozen

518 until they were processed for DNA analyses. A list of samples and age estimates is given in

519 Supplementary Data 1.

520 In July 2009 we sampled soil from sites representing moist tundra and steppe vegetation from

521 seven different locations in Yukon Territory, North-western Canada (Extended Data Table 3).

522 Intact soil cores were excavated in 15 or $30 \mathrm{~cm}$ (depending on depth of the A-horizon or the

523 active layer over the permafrost) PVC tubes with a $5 \mathrm{~cm}$ diameter inserted into a hollow steel

524 auger forced vertically into the ground. PVC tubes were closed with close-fitting lids and

525 transported in an electric cooler to Whitehorse where they were temporarily stored at $5^{\circ} \mathrm{C}$ before

526 they were shipped to Centre for GeoGenetics, University of Copenhagen, for processing. From

527 each soil core the five top and bottom cm were processed. Additionally, the moss layer, when

528 present, was processed from tundra samples. Sample material from each layer was homogenized

529 before subsamples were taken for nematode extraction. Bulk density varies greatly between

530 moss, peat and soil, hence the weight of extracted fractions vary between the different sample

531 materials. Nematodes were extracted from 2.0-10.0 $\mathrm{g}$ of sample material for $48 \mathrm{~h}$ by a modified

532 Baermann tray method ${ }^{53}$. Nematodes were heat-fixed $\left(80^{\circ} \mathrm{C}\right)$ in $4 \%$ formaldehyde, and a

533 minimum of 100 individuals per sample was identified to genus or family using a compound

534 microscope at $1000 \times$ magnification. 
535 Ancient megafauna intestinal/stomach contents and coprolites were collected directly from

536 permafrost and from permafrost-preserved animals (Extended Data Table 6). Interior parts were 537 sampled for DNA analyses.

\section{$538 \quad 2.0$ Chronology methods}

539 For the majority of samples, plant fragments and soil matrix organics extracted from sediment

540 samples using protocols described in e.g. ${ }^{56}$ were radiocarbon-dated using accelerator mass

541 spectrometry. ${ }^{14} \mathrm{C}$ ages were calibrated with the IntCal09 calibration curve ${ }^{41}$, or (in the case of

542 modern or near-modern soil samples) using the record of post-bomb atmospheric ${ }^{14} \mathrm{C}$

543 concentrations. Modern samples yielded ${ }^{14} \mathrm{C}$ concentrations over $100 \mathrm{pMC}$ (percent modern

544 carbon), which matched variations in the 20th century atmospheric carbon related to nuclear

545 testing and other enrichment ${ }^{57}$. In the case where a series of ages from one profile was available,

546 age-depth models were calculated, using the free-shape algorithm published by ${ }^{58}$, allowing

547 undated samples to be assigned ages. Age models were only applied to sequences for which

548 stratigraphic evidence supported continuous accumulation of sedimentary units. For a few

549 sequences with previously ascribed dates, calibrated ages were assigned based on the calibration

550 routine available at www.neotomaDB.org. ECOCHANGE radiocarbon ages and supporting

551 information are contained within the dating table of the ECOCHANGE meta-database (see

552 above).

\section{$553 \quad$ 3.0 DNA extraction, amplification and sequencing}

554 DNA extraction of permafrost samples and coprolites and intestinal/stomach contents followed

555 the protocols of ${ }^{11,59,60}$. For construction of the new northern boreal plant reference library, DNA

556 was extracted from leaves taken from taxonomically verified museum specimens originating

557 from across the circumboreal region and sequenced for the plastid $t r n \mathrm{~L}$ intron, following the

558 protocols of ${ }^{14}$.

\section{$559 \quad 3.1$ Amplification of plant DNA from sediments}

560 For the ancient plant DNA from sediments, PCR amplification was done using nine base-pair

561 tagged generic plant primers ${ }^{41}$ for the $\mathrm{P} 6$ loop of the $\operatorname{trn} \mathrm{L}$ plastid region (GH primers). We did 
562 not use the two standard barcoding markers $r b c \mathrm{~L}$ and $m a t \mathrm{~K}$ in this study, despite the extensive

563 reference database available, as they are not appropriate for working with degraded DNA, as

564 demonstrated in ${ }^{12}$. First, these markers are too long (c. $500 \mathrm{bp}$ for rbcL and $800 \mathrm{bp}$ for matK) for

565 reliably amplifying degraded DNA, and second, it is not possible to shorten them by designing

566 versatile primers on protein-coding genes. Hence some short amplification products can be

567 obtained, but with a strong bias among plant groups according to the variations of the primer

568 target sequences.

569 Each trnL tag was distinguished from any other tag by at least three base differences. The list of 570 tags was generated using the oligoTag program ${ }^{61}$. In order to increase the taxonomic resolution 571 of the analysis for three plant families, three additional primer pairs were used:

572 ITS1-F: GATATCCGTTGCCGAGAGTC ${ }^{62}$

573 ITS1Poa-R: CCGAAGGCGTCAAGGAACAC ${ }^{62}$

574 ITS1Ast-R: CGGCACGGCATGTGCCAAGG ${ }^{62}$

575 ITS1Cyp-R: GGATGACGCCAAGGAACAC, this study.

576 They target the first internal transcribed spacer (ITS1) of nuclear ribosomal DNA in Poaceae

577 (ITS1-F and ITS1Poa-R), Asteraceae (ITS1-F and ITS1Ast-R) and Cyperaceae (ITS1-F and

578 ITS1Cyp-R). These primers were tagged in the same way as the P6 loop primers to allow the 579 assignment of sequence reads to the relevant sample. PCR conditions followed the protocol of ${ }^{12}$.

580 Each permafrost and modern soil sample was amplified five times with the $g h$ primer pair and 581 once with each of the ITS1 primer pairs. Amplicons were sequenced using the Illumina GA IIx 582 platform as $2 \times 108$ base pairs (bp) pair end reads.

\section{$583 \quad 3.2$ Amplification of plant DNA from coprolites and intestinal/stomach contents}

584 DNA amplifications were carried out with the $\operatorname{trn} \mathrm{L} g h$ primers ${ }^{17}$ with MID incorporated tags.

585 For each sample, PCR was carried out twice with the same-tagged primers and with the use of $586 \mathrm{HiFi}$ (Invitrogen) polymerase and $5 \mathrm{ul}$ of extract with 50 cycles of PCR. PCR products were 587 pooled equimolarly and subsequently sequenced on the Roche FLX DNA sequencing platform 
588 (Copenhagen) following previously established protocols ${ }^{12}$. 16SMamm1 and 16SMamm2

589 primers ${ }^{63}$ were used to PCR DNA from the environmental faeces extracts, and the amplicons

590 cloned in order to identify the species of origin.

\section{$591 \quad 3.3$ Amplification of megafauna DNA from sediments}

592 For megafauna DNA in permafrost, PCRs were performed in the ancient DNA laboratory of the

593 Natural History Museum at the University of Oslo, using the 16Smam1 and 16Smam2 primers ${ }^{64}$

594 and a human-specific blocking primer (16Smam_blkhum $3{ }^{59}$ ). Fusion primers containing the

595 Lib-L forward and reverse primers (Roche 454) were used, and 16Smam1 included a Multiplex

596 Identifier (MID) sequence to allow multiplexing of PCR products for sequencing. PCR mixture

597 and profile were as described in ${ }^{59}$. All samples, including extraction blanks, were amplified a

598 maximum of six times in an attempt to obtain two positive PCR replicates, where positive PCRs

599 are those that produced a visible band of the correct size on an agarose gel. When successful, the

600 two PCR replicates were combined, and purified and normalised together using Sequalprep ${ }^{\mathrm{TM}}$

601 Normalisation plates (Invitrogen).

602 The purified PCR products were sequenced on three machines following the manufacturer's 603 guide for amplicon sequencing. All the plant $t r n \mathrm{~L}$ introns and ITS products were sequenced on

604 the Illumina GA IIx platform, the Norwegian Sequencing Centre was used for sequencing of 605 megafauna DNA (Roche 454 GS FLX Titanium).

\subsection{Amplification of nematode DNA from sediments}

607 For nematodes, PCR amplification was attempted on a subset of samples using two primer sets.

608 The Cep (fw primer CepF: 5'-CCGATAACGAGCGAGACTC-3', rv primer CepR 5'-

609 CGGCTAAACACCGAAAATCC-3') and Ter (fw primer TerF: 5'-

610 GCTCTCAAGGTGTATATCGC-3', rv primer TerR: 5'-AAACCAGCAGTATTAGCC-3')

611 primers target a $90 \mathrm{bp}$ region of the $18 \mathrm{~S}$ rDNA of the Cephalobidae and a $118 \mathrm{bp}$ region of the

612 18S rDNA of the Teratocephalidae, respectively. All primers were flanked by the Lib-L fw and

613 rv primers (Roche 454), and the 5' primers were further flanked by an 8-bp DNA tag ${ }^{65}$. PCRs

614 were performed with $2 \mu \mathrm{l}$ template DNA in a mixture described by ${ }^{6}$ under the following

615 conditions: initial denaturation at $94^{\circ} \mathrm{C}$ for $5 \mathrm{~min}$, followed by 65 cycles of denaturation at $94^{\circ} \mathrm{C}$ 
616 for $30 \mathrm{~s}$, annealing at $52^{\circ} \mathrm{C}$ or $50^{\circ} \mathrm{C}$ for Cep and Ter primers, respectively, for $30 \mathrm{~s}$, and extension

617 at $68^{\circ} \mathrm{C}$ for $30 \mathrm{~s}$. Cycling was completed at $72^{\circ} \mathrm{C}$ for $7 \mathrm{~min}$. PCR products of the correct size

618 (checked on a 2\% agarose gel) were purified using the QIAquick Gel Extraction kit (Qiagen)

619 according to the manufacturer's protocol. PCR reactions were repeated at least three times; five

620 times for samples that failed to produce amplicons using either of the primer pairs.

\section{$621 \quad 4.0$ Taphonomy and contamination issues}

$622{ }^{66}$ recently emphasized the need to understand the taphonomy of a palaeo-proxy system. Here

623 we further assess taphonomic bias and possible contamination of the samples. Fossil

624 assemblages do not represent life assemblages exactly due to post-mortem processes, including

625 differential decomposition, depositional changes, and addition of removal of material ${ }^{63}$. Our

626 landscape-scale taphonomic model for plant DNA derives it from in situ burial of above- and

627 below-ground plant parts, downslope transport of material in above-ground and below-ground

628 flow as particles or with DNA as part of soil-water colloidal complexes, and possible deposition

629 from a vector such as animals or wind. Tests in Svalbard (ECOCHANGE, unpublished data)

630 indicate that local $\left(3-50 \mathrm{~m}^{2}\right)$ sources provide almost all plant DNA in modern soils.

631 For yedoma, the surface vegetation was rooted in an accreting substrate that had insufficient time

632 for full profile development prior to burial and freezing (e.g., inceptisols, see ${ }^{67}$. The active layer

633 (estimated at $\sim 50 \mathrm{~cm}$ for the LGM of Alaska by ${ }^{67}$ acts as a time-averaging moving window, with

634 penetration of unfrozen material to a level by roots potentially occurring until the freezing front

635 reaches that level. We estimate that most yedoma samples record DNA over $\sim 1000 \mathrm{yr}$ of

636 accumulation, but with a bias toward the first few hundred years, this based on observations on

637 how deeply roots penetrate modern soils and average accumulation rates of sediment. We also

638 tested for differences in accumulation rate between time periods that might lead to bias in

639 diversity estimates ${ }^{68}$ (Supplementary Data 1). There was no significant difference between pre-

640 LGM and LGM rates (1.12 and $1.25 \mathrm{~mm} \mathrm{yr}^{-1}$, respectively). The post-LGM had significantly

641 greater average rates $\left(3.82 \mathrm{~mm} \mathrm{yr}^{-1}\right)$, but this estimate is based on only a few sites and samples

642 and more diverse forms of sedimentation; furthermore, beta diversity increases, rather than

643 diminishes, as would be expected if there were bias, in the post-LGM. We conclude that time-

644 averaging effects in our samples have not biased the diversity estimates. 
645 Peat and lacustrine sediment samples will have finer (decadal) temporal resolution as

646 demonstrated by numerous other proxy studies, and the loess-derived sediments sampled beneath

647 the rapidly deposited Dawson tephra at Quartz Creek (see section 8.3) may be time-averaged

648 over only decades or centuries. The few samples drawn from thermokarst lake deposits could

649 potentially include a wider age range of material derived from lake-bank collapse, but the

650 Holocene ${ }^{14} \mathrm{C}$ chronologies suggest that these sequences can be reliably compared with the late-

651 Pleistocene records.

652 The study by ${ }^{12}$ showed that graminoid DNA occurs in soil in about the same proportions as 653 graminoids occupy the above-ground biomass. We might expect woody plants to release 654 environmental DNA at a lower rate in relation to their above-ground biomass as much of their 655 production goes into woody stems and roots, which have a relatively slow rate of decomposition; 656 this is in the case, with woody taxa, when at low proportions in the biomass, being under657 represented in DNA by a ratio of approximately 5:1. Pollen and macrofossil data from numerous 658 sites including our own attest to the rarity of woody taxa in the pre-LGM and LGM periods. In 659 these two periods, woody taxa are likely under-represented in our DNA record, but even 660 allowing for this they still form a minor component of all assemblages.

$661{ }^{12}$ show forbs to be represented in DNA compared with above-ground biomass at a ratio of about 662 2:1. ${ }^{12}$ suggest that this difference may reflect different litter turnover rates; graminoids are richer 663 in lignins than are forbs ${ }^{69}$. Alternatively, forbs may invest resources into below-ground parts if 664 they are perennials while others (not many in the Arctic) are annuals and largely decompose 665 every year, yielding a range of root-shoot ratios ${ }^{70}$. It is unlikely that differential preservation of 666 ancient forb tissue has occurred because this would predict a lessening of forb dominance 667 through time; rather there is continuous forb dominance through the pre-LGM and LGM and an 668 abrupt diminution of forb DNA in the post-LGM. Further, there is no bias in the length of 669 sequences recovered through time (see below), which could otherwise conceivably generate a 670 bias as some of the longer $\operatorname{trn} \mathrm{L}$ sequences occur in the Cyperaceae.

671 Established protocols for permafrost sampling were followed to control for sample-based 672 contamination $5,6,11,53,54$. All ancient pre-PCR work (i.e. sub-sampling, extraction, and PCR set 673 up) was conducted in full body suits in state-of-the-art dedicated ancient DNA laboratories in 
674 Copenhagen and Oslo that are physically separated from any other biological laboratories, with 675 positive air pressure and nightly UV-exposure of surfaces, and equipped with positive flow 676 hoods. Occasionally, common contaminants were detected: Homo sapiens, Mus musculus, Sus,

677 Bos, Canis, Felis cattus, Solanum lycopersicum, Zea mays and Cedrus. The current control setup 678 does not allow contamination of individually tagged PCR products to be detected. To mitigate 679 this problem we removed haplotypes which have previously been detected as contaminants in 680 PCR reagents, are exotic to the study sites, or represented likely artificial diversity caused by 681 sequencing-error-by-products of contaminant or exotic haplotypes. The taxonomic assignment of 682 these sequences includes for example Rutaceae, Solanaceae, Solanoideae, Loasaceae and 683 Musaceae. Additionally, the following plant MOTUs occurred in sequencing blanks: Salicaceae 684 (Group 1), containing Populus and Salix; Equisetum (Group 2), containing E. arvense, E. 685 sylvaticum, and E. fluviatile; and Taraxacum. These MOTUs are likely to genuinely occur in the 686 study samples but were excluded as a conservative measure. We also note that Eritrichium, 687 (Group 1) Triticeae (Group 1), containing Elymus spp., Leymus spp., Apiaceae (Group 1), Betula 688 (Group 1), Dryas (Group 1) though not found in the bank controls of this study, have been 689 recorded as possible sources of contamination in other studies.

690 Importantly, to avoid possible contamination from re-deposition of organics or DNA in the 691 exposures sampled, we did not include any low-abundance sequences in the analyses (see 692 below), as such sequences may be due to re-deposition of material ${ }^{16}$.

693 For further evidence of reliability of results and their interpretations please see section 5.3

694 MOTUs characterization and data consistency.

695 All the raw and filtered data concerning plants, nematodes and megafauna are available from the 696 Dryad Digital Repository: http://doi.org/XXXXXX/XXXXXX.

697 5.0 Plant DNA reference libraries, sequence groupings and MOTU characterization

$698 \quad 5.1$ DNA reference libraries

699 We identified plant sequences retrieved from the ancient samples taxonomically using (i) the 700 arctic plant $t r n \mathrm{~L}$ reference library developed by ${ }^{14}$, comprising 842 species representing all 
701 widespread or ecologically important taxa of the circum-arctic flora, (ii) a new extension of this

702 library constructed by sequencing the nuclear ribosomal ITS1 region to improve species

703 resolution in three families (Cyperaceae, Poaceae and Asteraceae), (iii) a new north boreal plant

$704 \operatorname{trn} \mathrm{L}$ reference library constructed by sequencing DNA extracted from 1332 herbarium

705 specimens representing 835 of the most common north circumboreal species, of which most also

706 occur in present-day arctic vegetation, and (iv) the EMBL database for sequences not matching

707 taxa contained in these three reference libraries. The specimens used to construct the new north

708 boreal library were sampled after taxonomic verification from the following collections:

709 Herbarium of the Natural History Museum, University of Oslo, Norway (O); Popov Herbarium,

710 Siberian Central Botanical Garden, Novosibirsk, Russia (NSK); National Herbarium of Canada,

711 Canadian Museum of Nature, Ottawa, Canada (CAN); and University of Alaska Museum of the

712 North (ALA). Quality checking and cleaning of this new library was performed by comparing all

713 sequences with published sequences using NCBI/BLAST and by phylogenetic analyses of each

714 family, including sequences from closely related taxa to verify taxonomic identity. All reference

715 databases are available from the Dryad Digital Repository: http://doi.org/XXXXXX/XXXXXX.

\section{$716 \quad 5.2$ Sequence groupings and identifications of sedimentary plant DNA}

717 For plant DNA data obtained from the sediment samples, each pair of reads was assembled to

718 reconstruct full-length marker sequence using the Solexapairend program from the OBITools

719 package (http://metabarcoding.org/obitools). Sequences were associated with their corresponding

720 sample according to the primer tags, and identical sequences were clustered to form molecular

721 operational taxonomic units (MOTUs). MOTUs occurring less than five times in the whole data

722 set or containing ambiguous base symbols were discarded. Only PCR repeats with more than

7231000 sequences for the $g h$ primers and 500 sequences for the ITS1 primers were considered for

724 the following process. For $g h$ PCR amplification, a MOTU was considered as belonging to a

725 sample if it occurred in the majority of the usable repeats for this sample. Taxonomic assignment

726 of MOTUs was done with the ecoTag program ${ }^{12}$ using our plant reference libraries as reference

727 databases: Only MOTUs having at least 95\% similarity with a sequence in one of the reference

728 libraries or in the EMBL database were kept in the final dataset. Identifications realized with our

729 reference libraries were given priority over EMBL. The final set of MOTUs associated with a

730 sample was based on all MOTUs retrieved from all repeats of this sample. Initial identifications 
731 to the species level were in some cases adjusted to a higher taxonomic level based on the

732 completeness of our reference libraries. Results are listed in Supplementary Data 2, 4 and 5.

\section{$733 \quad 5.3$ MOTUs characterization and data consistency}

734 Basic statistics were used to check data consistency among time periods. Results are presented in

735 Extended Data Figure 2a-c, and clearly show that older samples did not present any bias

736 compared with more recent samples. A bias could have been introduced (i) if the size of the $\operatorname{trn} \mathrm{L}$

737 P6 loop would have been smaller in taxa identified in older samples, (ii) if the number of

738 identified taxa were smaller in older samples, or (iii) if the number of sequence reads were lower

739 in older samples. This was not the case and we conclude that the reconstructed plant assemblages

740 from different time periods did not suffer from such biases.

741 We also checked if the primers used could explain the differences observed between forbs and

742 graminoids. The WebLogos ${ }^{51}$ presented in Extended Data Figure 2d show that the target

743 sequences of the $\operatorname{trn} \mathrm{L} g h$ primers ${ }^{42}$ are very well preserved in the main families leading to the

744 estimation of the relative proportions of forbs and graminoids. According to the very good match

745 of the $g h$ primers in the different families, it is highly unlikely that these minor differences can

746 produce any significant bias in the observed proportions of forbs and graminoids.

747 Finally, we carried out length statistics of the P6 loop of the $t r n \mathrm{~L}$ intron for several plant families

748 (Extended Data Table 2), knowing that shorter sequences are likely to be preferentially amplified

749 than longer sequences. According to the mean length in the different families, Cyperaceae

750 (graminoid) might be under-represented in our results, and Plumbaginaceae (forb) and

751 Polygonaceae (forb) over-represented. In any case, the bias was identical for all samples

752 (permafrost and diet), and for all periods as no size difference among the amplified sequences

753 were observed among period (Extended Data Figure 2a-c). For all the other families, the size

754 difference is minor, and is unlikely to generate any significant bias.

$755 \quad 5.4$ Reliability of the $\operatorname{trn} \mathrm{L}$ approach for estimating the diet of herbivores

756 To test the reliability of the $\operatorname{trn} \mathrm{L}$ approach for estimating the diet of herbivores, we conducted an 757 experiment on sheep. During the period of May-July 2011, pure plots of white clover (Trifolium 
758 repens, cv Merwi) and ryegrass (Lolium perenne, cv Aberavon) were used to test five mixtures

759 of green fodder (i.e. five diets differing by their clover:ryegrass ratios of 0:100, 25:75, 50:50,

$760 \quad 75: 25$ and 100:0).

761 The five diets were allocated to five 1-year-old Texel sheep fed ad libitum. For each sheep and 762 each diet, one rumen sample was collected on 2 successive days. The collection started 13 days 763 after the beginning of the diet in order to prevent from an effect of the previous diet. Each of the

76450 samples consisted of about $5 \mathrm{~g}$ of rumen content.

765 Total DNA was extracted from about $25 \mathrm{mg}$ of rumen content with the DNeasy Blood and Tissue 766 Kit (QIAgen GmbH, Hilden, Germany) following the manufacturer's instructions. The DNA 767 extracts were amplified with the $t r n \mathrm{~L} g h$ primers (g: GGGCAATCCTGAGCCAA; h:

768 CCATTGAGTCTCTGCACCTATC ${ }^{24}$ ) targeting a short portion of the $\operatorname{trn} \mathrm{L}$ intron of the 769 chloroplast DNA. For each sample two independent PCR replicates were carried out. Paired-end 770 sequencing (100 nucleotides on each extremity of the DNA fragments) was carried out at the 771 French National Sequencing Centre (CEA Genoscope, Evry, France) on a Illumina HiSeq 2000

772 (Illumina Inc.).

773 A total of 216,586 and 163,328 sequence reads corresponded to Trifolium repens (forb) and to 774 Lolium perenne (graminoid), respectively. The Pearson correlation coefficient between the actual 775 fraction of forb in diet and the proportion of forb estimated using the DNA-based approach is 776 highly significant $\left(\mathrm{r}^{2}=0.75, p<10^{-15}\right)$ (Fig. 4e).

777 All the data concerning the sheep diet experiments are available from the Dryad Digital 778 Repository: http://doi.org/XXXXXX/XXXXXX.

\section{$779 \quad 6.0$ Analysis of MOTU assemblage data}

780 Each sediment sample provided a molecular characterization of a local plant assemblage. To 781 analyse gross changes in plant assemblages through space and time we used 242 dated samples

782 from 21 sites (56 entities, i.e., individual sections), which provided a total of 7,738,725

783 chloroplast trnL (UAA) intron reads. For these analyses we used only the MOTUs identified

784 with the $g h$ primers (see Section 3.0), because the reads of these MOTUs are proportional to 
785 vegetation (see ${ }^{12}$ ). In total, 154 taxa (MOTUs) were identified, of which 47 were assigned to 786 species level (Supplementary Data 4). Supplementary Data 5 lists the MOTUs and constituent 787 taxa for the ITS identifications.

\section{$788 \quad 6.1$ Temporal classification of samples and data robustness}

789 Each sample was allocated to one of three broad age categories: (i) 50-25 thousand years ago 790 (kyr; pre-LGM), a period of fluctuating climate ${ }^{71}$; (ii) $25-15 \mathrm{kyr}$, the Last Glacial Maximum 791 (LGM), a period of constant cold and dry conditions ${ }^{17}$; (iii) $15 \mathrm{kyr}$-present, the current 792 interglaciation (post-LGM), which, subsequent to deglacial warming, is characterised by climate

793 stability and relatively high temperatures ${ }^{71}$. Our specification of LGM timing represents a period

794 between the transition of Marine Isotope Stage (MIS) 3 to MIS 2 and the transition to the Bølling

795 (Gi-1e). This time window incorporates the period of lowest global sea level, which is

796 traditionally used to define the LGM (22-18 kyr), along with flanking periods during which the

797 development of glaciation or deglaciation occurred. The use of a fairly wide window was also

798 intended to allow for some regional variation in the timing of the maximum. We assessed the

799 robustness of our analyses to alternative definitions of LGM timing using Permanova

800 (implemented using R package vegan ${ }^{72}$ ) to test the fit of models including LGM specifications

801 with different duration and timing, falling in the range 30-11 kyr. In general, there were not

802 large differences between many of the alternative definitions, and all detected the large shifts in

803 plant assemblages occurring around that time (Supplementary Data Table 3). To assess whether

804 our temporal definition of post-LGM masked changes prior to and including the onset of the

805 Holocene at $\sim 11 \mathrm{kyr}$, we extracted the post-LGM subset of data, i.e. 15-0 kyr, and used

806 Permanova to test whether splitting the data into two time periods (15-11 and 11-0 kyr)

807 improved the fit. The results indicated that given the data we have, the split of post-LGM into

808 two consecutive time bins did not significantly improve the null model $(P=0.08)$.

809 We compared our approach of defining a priori groups based on radio carbon dating with an 810 unsupervised approach whereby variation between samples was used to define groups. To

811 partition samples into clusters we used k-means clustering with the Hartigan-Wong algorithm,

812 values of $\mathrm{k}$ between 2 and 10 and 100 random starting configurations for each value of $\mathrm{k}$. The

813 Calinski-Harabasz criterion was used to identify the best supported values of $\mathrm{k}^{73}$.The results of 
814 unsupervised clustering largely coincided with our supervised analysis (Extended Data Figure 3

815 a-d). The two- and three-cluster solutions, which were best supported, revealed the clearest

816 distinction between post-LGM communities on one hand and pre-LGM and LGM samples on the

817 other. This is in accordance with our diversity analysis, which showed that that the species list of

818 the LGM was essentially a subset of the pre-LGM species list, although considerably fewer

819 species were recorded from LGM samples. The higher values of k indicated more subtle

820 differences between LGM and pre-LGM samples.

821 As a further investigation of data robustness, we repeated the analyses, but imposed an upper

822 limit of $40 \mathrm{kyr}$ to the pre-LGM period and excluded older samples, thus equalizing the duration

823 of the pre- and post-LGM periods (both 15,000 years). The results of these analyses were

824 qualitatively identical to those based on the whole data set. However, while MOTU richness

825 remained highest in the pre-LGM in the equalized analysis, it was less clearly so (equalized

826 analysis: total richness: pre-LGM = 103, $\mathrm{LGM}=48$, post-LGM = 74; jackknife second order

827 estimator: pre-LGM = 169, $\mathrm{LGM}=85$, post-LGM = 159).

\section{$828 \quad 6.2$ Functional characterization of molecular taxa}

829 We characterized MOTUs in terms of their coarse growth form; 147 of the 154 taxa identified

830 could be placed into four primary groups: forbs, graminoids (grasses + sedges + rushes), dwarf

831 shrubs or other woody plants (i.e., shrubs and trees). Information on growth form was derived

832 from BiolFlor, a database covering more than 60 plant species traits for 3659 plant species from

833 the German flora ${ }^{49,74}$. Where data were lacking, we excluded the taxon from analysis.

\section{$834 \quad 6.3$ Assemblage variation in time and space}

\section{$835 \quad$ 6.3.1 Ordination}

836 Variation in assemblage characteristics among time periods was visualised using two-

837 dimensional non-metric multi-dimensional scaling (NMDS). The composition of samples was

838 estimated by the proportion of reads corresponding to particular MOTUs.

839 Dissimilarity between pairs of plant assemblages was defined using Bray-Curtis 
840 dissimilarity $(\mathrm{BC})^{44}$. For some analyses similarity was calculated as 1-BC. Bray-Curtis

841 dissimilarity is frequently used in plant community ecology and is recommended by several

842 basic sources due to its properties ${ }^{75} \mathrm{pg} 51$ and elsewhere ${ }^{72,76,77}$. In particular, Bray-Curtis shows a

843 good ability to mirror environmental distances ${ }^{75,78} \mathrm{pg}$ 50-54. The Bray-Curtis index also works well

844 with proportional abundance data ${ }^{78,79} \mathrm{pg} 287$. Euclidean distance is also widely used with

845 proportional abundance data. While so-called proportion indices like BC depend on the number

846 of shared species and thus measure distance as proportions of the maximum distance possible,

847 Euclidean distance concentrates only on differences in relative proportional abundances ${ }^{80}$. Thus,

848 the choice of distance measure depends on the emphasis of a particular study, e.g. how much

849 attention is paid to different aspects of community assemblage structure. We considered the co-

850 occurrence of taxa in samples to be an important feature of palaeocommunity assembly, and this

851 is why Bray-Curtis was our primary choice. However, since Euclidean distance could add

852 another aspect of community assembly, we performed a parallel analysis (Permanova, NMDS

853 and distance decay) using Euclidean distance. We found that our quantitative results and the

854 qualitative patterns were robust to the choice of distance measure.

855 First, the ordination was conducted for the whole data set. Second, since the spatial distribution

856 of the total data set was not balanced between time periods, we identified four replicated

857 locations (two in North America, one in western Siberia, one in eastern Siberia) where samples

858 were collected from sites within $100 \mathrm{~km}$ of each other in all palaeoclimatic periods. We based a

859 further ordination on an equal number of samples per location per period (15 samples per period,

86045 samples in total). Because the results of analyses based on the two data sets coincided, only

861 the results of the first analysis are presented, except in Extended Data Figure 3e where it was

862 impossible to portray all 242 samples and the results of the second analysis are presented. Stress

863 values for the ordinations were in the range $0.05-0.17$. Permanova was used to compare the

864 similarity of floristic composition in different periods.

\section{$865 \quad$ 6.3.2 Richness estimation}

866 Nonparametric richness estimators are usually recommended due to their precision and low

867 susceptibility to sampling bias ${ }^{81}$. In particular, the second order jackknife has been shown to be 868 one of the most effective estimators ${ }^{82,83}$, especially for highly sparse palaeontological data ${ }^{84}$.

869 We used the second order jackknife to estimate species richness in climatic periods. 


\subsubsection{Distance-decay measures}

871 We modelled variation in plant communities using a distance-decay in similarity approach ${ }^{48}$,

872 using as a dependent variable all pairwise similarities between samples in terms of floristic

873 composition. We used a generalised linear model to describe variation in the dependent variable.

874 The dependent variable was bounded by 0 and contained a large proportion of exact 0 s (i.e.

875 achieved when pairs of samples contained no shared taxa). The data were also theoretically

876 bounded by 1 , but in practice no samples were identical and the data exhibited a strong positive

877 skew. To adequately model variation in such a dependent variable, we used a compound Poisson

878 error distribution (using R package tweedie ${ }^{85}$ ), with an index parameter for the power variance

879 function of 1.45 (estimated using maximum likelihood) and a log link function. The geographic

880 distance separating points was included as an independent variable. This distance was calculated

881 as the natural logarithm of the orthodromic distance between points, i.e. calculated as the shortest

882 earth-surface distance between two sets of latitude and longitude coordinates (the earth was

883 assumed to be spherical with a radius of $6371 \mathrm{~km}$ ). The second independent variable consisted of

884 a categorical variable representing the combination of the time periods being compared. Thus,

885 this variable had six levels, consisting of all pairwise combinations between these periods (pre-

886 LGM $v s$ pre-LGM, pre-LGM $v s$ LGM, pre-LGM $v s$ post-LGM etc.).

887 An interaction term between the independent variables was included in the model. Since each

888 sample was represented multiple times in the data set, observations were not independent,

889 biasing model estimates of variance and statistical significance. To estimate the true significance

890 of model terms, we recalculated each model a further 999 times using data sets where the

891 community data underlying the dependent variable were randomised (values were permuted

892 within samples using the permatfull function from the R package vegan). The change in deviance

893 associated with dropping a term in the empirical model was then compared to the corresponding

894 statistics derived from randomised models; significance was estimated based on the number of

895 randomised statistics higher than the empirical value.

896 6.3.4 Randomisation tests used to assess functional changes between time periods 
897 We used a randomisation procedure $\left(\mathrm{BC}_{\text {diff }}\right.$; described in $\left.{ }^{86}\right)$ to assess whether the growth form 898 composition of plant communities of the LGM and post-LGM (target) periods represented a 899 random sample from the directly preceding (source) period. To do this we calculated the BC

900 between the observed mean growth form composition of the target period and each of 999 means

901 derived from a bootstrapped selection (sampled with replacement; the sample size corresponding

902 to that of the target period) of samples from the source period ( $\mathrm{BC}\left[\right.$ observed $v s$ random] $=\mathrm{BC}_{\text {or }}$ ).

903 In parallel, BC was calculated 999 times between two random means, calculated as described

904 above $\left(\mathrm{BC}[\right.$ random $v$ s random $\left.]=\mathrm{BC}_{\mathrm{rr}}\right)$. The latter calculation provided a population of $\mathrm{BC}$

905 measures that might be expected to arise by chance. The vector of $999 \mathrm{BC}_{\mathrm{rr}}$ values was

906 subtracted from the vector of $999 \mathrm{BC}_{\mathrm{or}}$ in a random pairwise manner to produce a final vector of

907999 values $\left(\mathrm{BC}_{\mathrm{diff}}=\mathrm{BC}_{\text {or }}-\mathrm{BC}_{\mathrm{rr}}\right) . \mathrm{BC}_{\text {diff }}$ has an expected value of 0 if community composition is 908 random.

909 This approach indicated that LGM growth form structure did not differ from a random draw

910 from the pre-LGM community (95\% quantiles of BCdiff; LGM: -0.14-0.11). However, post-

911 LGM growth form composition was not a random subset of that from the LGM (95\% quantiles

912 of BCdiff: 0.05-0.30). The abundance of forbs decreased while the abundance of all other

913 growth form types increased in the post-LGM compared with the LGM period (Extended Data

914 Figure $3 \mathrm{~g})$.

\section{$915 \quad$ 6.3.5 Overview of vegetation change through time}

916 We classified a subset of samples (those of finite age) into 5000-year age classes (from 50,000-

91745,000 to 5000-0 kyr) across the region encompassing central and northeast Siberia and Alaska-

918 Yukon. These regions were unglaciated and inhabited by the megafauna in the Pleistocene, and

919 they are the regions from which the dietary samples originated. The samples from Svalbard used

920 in the previous analyses were omitted here as Svalbard was almost entirely glaciated in the LGM

921 and did not host megafauna. We plotted the abundance of the key groups (described above) as

922 estimated by the abundance of DNA sequence reads through time to provide an overview of their

923 shifting importance. We also calculated the number of MOTUs detected for each group through

924 time (Extended Data Figure 3h). 


\subsection{Filtering and taxonomic inference of nematode and megafauna data}

\subsection{Nematode data}

927 Nematode sequences were sorted according to the DNA tag used. Within individual PCR

928 products, sequences represented by less than five reads were discarded. The remaining sequences

929 were assigned to taxa using the statistical assignment package SAP ${ }^{87}$.

930 We used Dufrêne-Legendre indicator species analysis ${ }^{23}$ to identify nematode taxa that acted as

931 good indicators of modern tundra or steppe habitat (as implemented by the indval function from

932 the R package labdsv ${ }^{88}$ ). The function calculates an indicator value for each taxon that is the

933 product of its relative frequency and relative average abundance in sample groups (the groups in

934 this case being steppe and tundra). The value varies from 0 to 1 and would be maximal if all

935 examples of a taxon were distributed among all samples from only one of tundra or steppe. By

936 morphologically determining the nematode faunas of 35 sediment samples from contemporary

937 tundra and steppe sites in Yukon, Canada, we discovered two indicator families:

938 Teratocephalidae for tundra and Cephalobidae for steppe. We tested whether the proportion of

939 the two families differed between tundra and steppe with a nested ANOVA (site nested within

940 vegetation type) (SAS Enterprise Guide, version 4). Data on proportions were square root

941 transformed to obtain homogeneity of variance (Bartlett test). The ANOVA was executed on

942 non-normally distributed data, but the ANOVA is quite robust to non-normality ${ }^{89}$. We

943 genetically determined the presence of the two indicator families in 17 of the 242 ancient

944 sediment samples; results are listed in Extended Data Table 4.

\section{$945 \quad 7.2$ Ancient megafauna sediment data}

946 Sequences were filtered and sorted using the programs included in the OBITools package

947 (http://metabarcoding.org/obitools). For filtering, only reads containing both primers and the tag

948 were kept in the data, permitting two errors in the primers and no errors in the tags. Filtering and

949 taxonomic identification was performed as described in ${ }^{59}$ with the following two adjustments:

950 (i) an additional denoising step using the program Obiclean was included ${ }^{90}$, and (ii) the

951 electronic PCR was performed on the EMBL standard sequences release 111. Within each

952 sample, only sequences represented by $>10$ reads and an identification to at least genus level 
953 with an identity $>0.95$ were kept in the final dataset. Identified taxa in each of the samples for

954 which plant data are available are given in Extended Data Table 5.

\section{$955 \quad 7.3$ Ancient megafauna diet data}

956 The plant DNA amplified from coprolites and intestinal/stomach contents was sorted using the

957 OBITools package (http://metabarcoding.org/obitools). Sequences shorter than 10 basepairs, or

958 containing ambiguous nucleotides, or with occurrence $\leq 5$ were excluded. Strictly identical

959 sequences were merged and taxonomic assignation was achieved using the ecoTag program and

960 reference libraries described in sections 5.1 and 5.2.Only unique sequences with an identity of

$961100 \%$ to at least one of the reference sequences were kept for further analysis. Where 100\%

962 identities were obtained from multiple reference libraries, priority was given to taxon assignment

963 using the Arctic and boreal libraries.

964 We obtained a total of 15,951 sequence reads that could be assigned to the eight coprolite/gut

965 samples using the MID tags, of which 1,663 reads were unique. Out of these reads, 13,735

966 passed filtering and a final 9,084 reads could be assigned with $100 \%$ identity to a plant species in

967 one of the reference databases. Sequence data and compositional data for the fossil diet samples

968 are given in Supplementary Data 6.

\section{8.0 Permafrost site information}

\section{$970 \quad$ 8.1 Published sites, Eurasia}

\section{Bol'shaya Balakhnaya, Buor Kaya and Khatanga, NW Siberia}

972 Three locations in NW Siberia with perennially frozen deposits are described in ${ }^{16}$. Buor Kaya is

973 located on the east side of the bay formed by the Lena Delta, is a 3-m exposure of sandy silt with

974 organic inclusions, interpreted as lacustrine sediment, Holocene in age. Khatanga material was

975 sampled from Holocene river terrace deposits $(<5 \mathrm{~m})$ along a small tributary stream. Material

976 ranged from clay, to weakly laminated sands and silts, to peat. Bol'shaya Balakhnaya is also a

977 Holocene fluvial terrace locality featuring weakly laminated sands and minor interspersed lenses 978 of peat and clay. 
981 These localities are described by ${ }^{6}$, who report perennially frozen sediments taken along the

982 shore of Lake Taimyr. Deposits are silt-dominated but range from organic to inorganic, and 983 massive to laminated; all sediments are of late-Pleistocene age ( 40 to $12 \mathrm{kyr}$ ). Further

984 stratigraphic information from the "type locality" of this type of sediment - the Cape Sabler site

985 - is provided in ${ }^{91}$. Sediment depth/age curves in ${ }^{6}$ show that depositional rates were in the order

986 of 1-2 mm/yr. This implies a high temporal resolution of the trapped macroflora elements and

987 other biogenic matter, as the ground surface rose due to the vertical accretion of silt and fine sand

988 that was transported and deposited by aeolian and surface runoff processes.

\section{Main River, E Siberia}

990 The Main River (Ice Bluff) exposure extends for about $1 \mathrm{~km}$ at an elevation of $30 \mathrm{~m}$ on the left

991 bank of the Main River. It has been previously reported by ${ }^{91}$ and ${ }^{93}$. The northern exposure, from

992 where our samples are derived, is dominated by ice-rich deposits interpreted as a facies of

993 yedoma by ${ }^{92}$. At the time of sampling, the lower portion of the exposure was covered by slump

994 material; the oldest exposed deposits are $\sim 40 \mathrm{kyr}$. We dated further samples to improve the

995 previously established chronology of the site (Extended Data Figure 1a). Samples form a

996 consistent progression suggesting continuous sedimentation without major hiatus between $\sim 40$

997 and $20 \mathrm{kyr}$.

\section{$998 \quad 8.2$ Unpublished sites, Eurasia}

\section{Taimyr Lake, Taimyr Peninsula, NW Siberia}

1000 A $3 \mathrm{~m}$ high cliff section at the western side om the Cape Sabler Peninsula. Vaguely laminated silt 1001 with some sand intrabeds. Four radiocarbon dates suggest a mid-Holocene age between 4.7-7.1

1002 kyr for the sediment sequence, except for the uppermost sample that is modern in age.

1003 Anadyr, E Siberia 
1004 Holocene deposits, beside the Anadyr River, $2 \mathrm{~km}$ West of Anadyr, Chukotka. Materials

1005 excavated from a pit lying 3.0-5.1 m above sea level.

1007 The site is the type section for the late Pleistocene in NE Siberia and has been much studied (e.g.

$\left.1008{ }^{94-96}\right)$. The extensive set of exposures runs for $\sim 4 \mathrm{~km}$ along the east bank of the Kolyma River

1009 and features high cliffs of yedoma (ice complex), dominated by silt and large syngenetic ice

1010 wedges, depressions representing the drained basins of thermokarst lakes (alasy), and large areas

1011 of slumped and partially vegetated material. The exposure we studied and sampled in 2009

1012 (Extended Data Figure 1b) is from the centre of remnant 7E of the yedoma surface identified by

$1013{ }^{94}$. We levelled in and logged 23 sections and sampled for DNA, radiocarbon and

1014 palaeoecological analysis from just above the Kolyma River level to $40 \mathrm{~m}$ above it.

1015 The sampled stratigraphic unit comprised yedoma sandy silty at least $34 \mathrm{~m}$ thick, underlying a 1016 thaw unconformity at a depth of $\sim 1.9 \mathrm{~m}$ below the ground surface (Extended Data Figure 1c).

1017 The yedoma unit was characterized by grey sandy silt to silty fine sand with low and varying

1018 amounts of organic matter, the most prominent of which were abundant fine in situ roots

1019 pervasive throughout the unit. The sediment is interpreted primarily as loess and contains a

1020 number of weakly developed palaeosols (J.B. Murton unpublished data). The upper $1.9 \mathrm{~m}$ of the

1021 sedimentary sequence comprised the post-glacial transition zone and overlying modern active 1022 layer.

$1023 \quad \mathrm{~A}^{14} \mathrm{C}$ age-depth model is presented in Extended Data Figure 1d. The upper part of the model, 1024 above an elevation of $20 \mathrm{~m}$ above river level, is considered to be robust, based on ${ }^{14} \mathrm{C}$ ages that

1025 decrease overall in stratigraphic order towards the top of the unit. ${ }^{14} \mathrm{C}$ ages from below $15-20 \mathrm{~m}$ 1026 above river level are close to the limit of radiocarbon dating, and the age-depth model of this 1027 lower part of the yedoma should be treated as less definitive, although supported by OSL age at $102814.5 \mathrm{~m}$. The basal units of the exposure are not represented in this study.

1029 Svalbard: Colesdalen and Endalen 
1030 Samples were taken from the upper organic horizon of tundra soils in two valleys directly into

1031 sterile tubes and sealed. Sites are Colesdalen and Endalen (Extended Data Figure 1e,f). Both

1032 valleys have vegetation dominated by mid-Arctic tundra.

\section{$1033 \quad$ 8.3 Published sites, North America}

1034 Zagoskin Lake, Alaska

1035 Zagoskin is a maar lake in western Alaska with sediments dating from 37 kyr BP. Details are

1036 reported in ${ }^{97,98}$. The sediments are relatively inorganic and dominated by silt, interpreted as loess

$1037{ }^{98}$. Loss on ignition values are generally $<10 \%$, except in the top $1.4 \mathrm{~m}$ of the 15 -m section.

1038 Biostratigraphic changes related to deglaciation ( 15 kyr BP) are recorded at $5 \mathrm{~m}$ depth.

1039 Sediments dating to the LGM are present.

1040 Quartz Creek, Yukon Territory, Canada

1041 This locality is described by ${ }^{99}$. Sections are exposed in mining cuts and comprise silt-rich facies

1042 and palaeosols. The silt is loess-derived and sometimes finely bedded, reflecting re-working.

1043 Samples are associated with the Late Pleistocene Dawson tephra ${ }^{99,100}$ and immediately underlie

1044 the bed, ranging from $31 \mathrm{kyr}$ BP to $30 \mathrm{kyr}$ BP, consistent with the Dawson tephra chronology.

1045 Goldbottom, Yukon Territory, Canada

1046 This locality also comprises several exposures in mining cuts and is described in ${ }^{101}$. Frozen silt-

1047 dominated sediments, interpreted as loess or retransported loess, and organic deposits are

1048 present, and the Dawson tephra provides a late MIS 3-ealry MIS 2 stratigraphic marker.

1049 Previous dating of the tephra at $c a .30 \mathrm{kyr}$ BP 101,102 are consistent with ages associated with the

1050 samples in this study. Samples at the site range include pre-LGM samples (ca. 45 to $27 \mathrm{kyr}$ BP)

1051 and early LGM ages (ca. 24 to $23 \mathrm{kyr} \mathrm{BP}$ ).

1052 Stevens Village, Alaska

1053 The locality is described in ${ }^{11}$. The exposure is $\sim 15 \mathrm{~m}$ high and lies on the Yukon River in central

1054 Alaska. Frozen silt, interpreted as loess, overlies basal fluvial gravel and contains interbedded 
1055 organic layers (regosols) dating to the early Holocene. A single sample collected from an early

1056 Holocene soil dates to $11.2 \mathrm{kyr}$ BP.

\subsection{Unpublished sites, North America}

1058 Purgatory, Alaska

1059 The Purgatory site is located a few kilometres upstream from the Stevens Village site and

1060 consists of aeolian sands with plant detritus. Two samples from near the base of the exposure 1061 date to the post-LGM interval.

1062 Ross Mine, Canada

1063 The Ross Mine site is located in the southern Klondike goldfields of central Yukon. One sample

1064 from a floodplain silt unit within fluvial deposits dates to the LGM, while the remaining samples, 1065 collected from within a Holocene peatland date to the post-LGM interval. 
1068 51. Crooks, G. E., Hon, G., Chandonia, J.-M. \& Brenner, S. E. WebLogo: a sequence logo 1069 generator. Genome Research 14, 1188-1190 (2004).

1070 52. Schirrmeister, L. et al. Sedimentary characteristics and origin of the Late Pleistocene Ice 1071 Complex on north-east Siberian Arctic coastal lowlands and islands - A review.

1072 Quaternary International 241, 3-25 (2011).

1073 53. Willerslev, E. et al. Ancient biomolecules from deep ice cores reveal a forested southern $1074 \quad$ Greenland. Science 317, 111-114 (2007).

1075 54. Epp, L. S. et al. New environmental metabarcodes for analysing soil DNA: potential for 1076

55. Vestergård, M. Nematode assemblages in the rhizosphere of spring barley ( Hordeum vulgare L.) depended on fertilisation and plant growth phase. Pedobiologia 48, 257-265 (2004).

56. Brock, F., Higham, T., Ditchfield, P. \& Ramsey, C. B. Current pretreatment methods for AMS radiocarbon dating at the Oxford Radiocarbon Accelerator Unit (ORAU). Radiocarbon 52, 103-112 (2010).

57. Hua, Q. \& Barbetti, M. Review of tropospheric bomb 14C data for carbon cycle

58. Goslar, T., Van der Knaap, W. O., van Leeuwen, J. \& Kamenik, C. Free-shape 14C age1086 depth modelling of an intensively dated modern peat profile. Journal of Quaternary Science 24, 481-499 (2009).

60. Haile, J. in Methods in Molecular Biology - Ancient DNA (Shaprio, B. \& Hofreiter, M.) 57-63 (Humana Press Series, 2012).

1093 61. Coissac, E. E. OligoTag: a program for designing sets of tags for next-generation 1094 sequencing of multiplexed samples. Methods Mol Biol 888, 13-31 (2012).

1095 62. Baamrane, M. A. A. et al. Assessment of the food habits of the Moroccan dorcas gazelle 

(2012).

63. Birks, H. J. B. \& Birks, H. H. Quaternary Palaeoecology. (London Edward Arnold, 1099 2004).

1100 64. Taylor, P. G. Reproducibility of ancient DNA sequences from extinct Pleistocene fauna. Molecular Biology and Evolution 13, 283-285 (1996).

1102 65. Binladen, J. et al. The use of coded PCR primers enables high-throughput sequencing of multiple homolog amplification products by 454 parallel sequencing. PLOS ONE 2,-

66. Jackson, S. T. Representation of flora and vegetation in Quaternary fossil assemblages: known and unknown knowns and unknowns. Quaternary Science Reviews 49, 1-15 (2012).

67. Höfle, C. \& Ping, C.-L. Properties and soil development of late-Pleistocene paleosols from Seward Peninsula, northwest Alaska. Geoderma 71, 219-243 (1996).

68. Tomašových, A. \& Kidwell, S. M. Predicting the effects of increasing temporal scale on species composition, diversity, and rank-abundance distributions. Paleobiology 36, 672695 (2010).

Cornelissen, J. H. C. et al. Global negative vegetation feedback to climate warming responses of leaf litter decomposition rates in cold biomes. Ecol Lett 10, 619-627 (2007).

Aerts, R. \& Chapin, F. S. I. The mineral nutrition of wild plants revisited: a reevaluation of processes and patterns. Advances in Ecological Research 30, 1-67 (1999).

72. Oksanen, J. Multivariate analysis of ecological communities in R: vegan tutorial. $R$

1122 73. Caliński, T. \& Harabasz, J. A dendrite method for cluster analysis. Communications in Statistics 3, 1-27 (1974).

1124 74. Kühn, I., Durka, W. \& Klotz, S. BiolFlor - a new plant-trait database as a tool for plant 1125 invasion ecology. Diversity and Distributions 10, 363-365 (2004).

1126 75. McCune, B., Grace, J. B. \& Urban, D. L. Analysis of ecological communities. (2002). 
1127 76. Clarke, K. R., Somerfield, P. J. \& Chapman, M. G. On resemblance measures for ecological studies, including taxonomic dissimilarities and a zero-adjusted Bray-Curtis coefficient for denuded assemblages. Journal of Experimental Marine Biology and Ecology 330, 55-80 (2006).

1131 77. Austin, M. P. Inconsistencies between theory and methodology: a recurrent problem in ordination studies. Journal of Vegetation Science 24, 251-268 (2012).

1133 78. Faith, D. P., Minchin, P. R. \& Belbin, L. Compositional dissimilarity as a robust 1134 measure of ecological distance. Vegetatio 69, 57-68 (1987).

1135 79. Legendre, P. \& Legendre, L. Numerical Ecology. (Elsevier, Amsterdam, 1998).

1136 80. Anderson, M. J., Connell, S. D. \& Gillanders, B. M. Relationships between taxonomic resolution and spatial scales of multivariate variation. J Anim Ecology 74, 636-646 (2005).

1139 81. Gotelli, N. J. \& Colwell, R. K. in Biological diversity: Frontiers in measurement and assessment (Magurran, A. E. \& McGill, B. J.) 39-54 (Oxford University Press, Oxford, 2011).

1142 82. Walther, B. A. \& Moore, J. L. The concepts of bias, precision and accuracy, and their use in testing the performance of species richness estimators, with a literature review of

83. Hortal, J., Borges, P. A. V. \& Gaspar, C. Evaluating the performance of species richness estimators: sensitivity to sample grain size. J Anim Ecol 75, 274-287 (2006).

1147 84. Vavrek, M. J. fossil: Palaeoecological and palaeogeographical analysis tools.

$1148 \quad$ Palaeontologia Electronica 14, 1T:16p (2011).

1149 85. Dunn, P. K. tweedie: tweedie exponential family models. $R$ package version 2.1.7 $1150 \quad$ (2011).

1151 86. Davison, J., Öpik, M. \& Daniell, T. J. Arbuscular mycorrhizal fungal communities in 1152 plant roots are not random assemblages. FEMS Microbiology Ecology 78, 103-115 1153 (2011).

1154 87. Munch, K., Boomsma, W., Huelsenbeck, J. P., Willerslev, E. \& Nielsen, R. Statistical 1155 assignment of DNA sequences using Bayesian phylogenetics. Systematic Biology 57, $1156 \quad 750-757$ (2008).

1157 88. Roberts, D. W. labdsv: ordination and multivariate analysis for ecology. R package 
version 1.5-0 (2007).

1159 89. Underwood, A. J. Experiments in ecology: their logical design and interpretation using

$1160 \quad$ analysis of variance. (Cambridge University Press, Cambridge, 1997).

1161 90. Shehzad, W. et al. Prey preference of snow leopard (Panthera uncia) in South Gobi,

$1162 \quad$ Mongolia. PLoS ONE 7, e32104 (2012).

1163 91. Möller, P., Bolshiyanov, D. Y. \& Bergsten, H. Weichselian geology and

1164 palaeoenvironmental history of the central Taymyr Peninsula, Siberia, indicating no

1165 glaciation during the last global glacial maximum. Boreas 28, 92-114 (1999).

1166 92. Kotov, A. N., Lozhkin, A. V. \& Ryabchun, V. K. Permafrost-facial conditions of the

1167 Upper Pleistocene deposit creation of the Main River valley (Chukotka). Forming of

1168 Relief, Correlated Deposit and Gravels of the Northern-east of USSR, SVKNII DVO AS

1169 USSR, Magadan 117-131 (1989).

1170 93. Kuzmina, S. A., Sher, A. V., Edwards, M. E. \& Haile, J. The late Pleistocene

1171 environment of the Eastern West Beringia based on the principal section at the Main

1172 River, Chukotka. Quaternary Science Reviews 30, 2091-2106 (2011).

1173 94. Sher, A. V. et al. Late Cenozoic of the Kolyma Lowland. XIV Pacific Science Congress, $1174 \quad$ Khabarovsk 1-116 (1979).

$117595 . \quad$ Wetterich, S., Schirrmeister, L. \& Kholodov, A. L. The joint Russian-German

1176 expedition Beringia/Kolyma 2008 during the International Polar Year (IPY) 2007/2008.

1177 Reports on Polar and Marine Research 636, 43 (2011).

1178 96. Zanina, O. G., Gubin, S. V. \& Kuzmina, S. A. Late-Pleistocene (MIS 3-2)

1179 palaeoenvironments as recorded by sediments, palaeosols, and ground-squirrel nests at

1180 Duvanny Yar, Kolyma lowland, northeast Siberia. Quaternary Science Reviews 30, $1181 \quad 2107-2123(2011)$.

1182 97. Ager, T. A. Late Quaternary vegetation and climate history of the central Bering land

1183 bridge from St. Michael Island, western Alaska. Quaternary Research 60, 19-32 (2003).

1184 98. Muhs, D. R., Ager, T. A., Been, J., Bradbury, J. P. \& Dean, W. E. A late Quaternary 1185 record of eolian silt deposition in a maar lake, St. Michael Island, western Alaska.

1186 Quaternary Research 60, 110-122 (2003).

1187 99. Sanborn, P. T., Smith, C. A., Froese, D. G. \& Zazula, G. D. Full-glacial paleosols in 1188 perennially frozen loess sequences, Klondike goldfields, Yukon Territory, Canada. 
Quaternary Research 66, 147-157 (2006).

100. Zazula, G. D., Froese, D. G., Elias, S. A. \& Kuzmina, S. Arctic ground squirrels of the mammoth-steppe: paleoecology of Late Pleistocene middens ( 24000-29450 14 C yr BP), Yukon Territory, Canada. Quaternary Science Reviews 26, 979-1003 (2007).

1193 101. Froese, D. G., Zazula, G. D. \& Reyes, A. V. Seasonality of the late Pleistocene Dawson tephra and exceptional preservation of a buried riparian surface in central Yukon Territory, Canada. Quaternary Science Reviews 25, 1542-1551 (2006).

102. Demuro, M. et al. Optically stimulated luminescence dating of single and multiple grains of quartz from perennially frozen loess in western Yukon Territory, Canada: comparison with radiocarbon chronologies for the late Pleistocene Dawson tephra. Quaternary Geochronology 3, 346-364 (2008).

104. Beilman, D. W. Holocene and recent carbon accumulation in Svalbard mires. Svalbard

103. Wetterich, S., Schirrmeister, L. \& Kholodov, A. L. The joint Russian-German expedition Beringia/Kolyma 2008 during the International Polar Year (IPY) 2007/2008. Reports on Polar and Marine Research 636, 43 (2011).

107. Harington, C. R. \& Eggleston-Stott, M. Partial carcass of a small Pleistocene horse from Last Chance Creek near Dawson City, Yukon. Current Research in the Pleistocene 13,

1213 108. Sulerzhitsky, L. D. \& Romanenko, F. A. Age and dispersal of 'mammoth' fauna in Asian Polar region (according to radiocarbon data). Kriosfera Zemli (Earth Cryosphere) 1, 12-

1216 109. Lazarev, P. A. Skeleton of the woolly rhinoceros from Churapcha. In: Labutin, Y. (ed.): 1217 Mammals of the Yakutian Anthropogene: 55-97; Yakutsk (Russian Academy of 1218 Sciences, Yakutian Scientific Centre) [in Russian] (1998). 
1219 110. Kosintsev, P. A., Lapteva, E. G., Korona, O. M. \& Zanina, O. G. Living environments

1220 and diet of the Mongochen mammoth, Gydan Peninsula, Russia. Quaternary International $1221 \quad 276,253-268(2012 b)$.

1222

1223

1224

1225

1226

1227 